\title{
Quantitative Metallography With a Digital Computer: Application to a Nb-Sn Superconducting Wire
}

\author{
G. A. Moore and L. L. Wyman
}

(November 20, 1962)

\begin{abstract}
Accurate quantitative data pertinent to the structure of solid materials at the micro size level, which are difficult or prohibitive to obtain by traditional manual measurements, are now obtained directly by a digital computer which uses a photomicrograph as the information input. The history of picture interpretation experiments at the National Bureau of Standards is reviewed. The fundamental computer operations are illustrated, together with a description of 24 image processing routines now functional at a practical level.

A micrograph of a specimen of $\mathrm{Nb}-\mathrm{Sn}$ superconductor wire is exhaustively analyzed. This specimen is found to contain approximately 70 percent $\mathrm{Nb}_{3} \mathrm{Sn}$, nearly all of which is mutually interconnected. It is also found that in this specimen the mean free path in the $\mathrm{Nb}_{3} \mathrm{Sn}$ superconducting phase is only 26.5 microns. This small value results from the spongy structure of the material and numerous interruptions caused by voids and by particles of four other solid phases. The comparative importance of the several types of interruptions is measured. It is determined that small voids are the most important single cause of the short mean free path, and deduced that these voids appear to have formed mainly from the reaction during heat treatment.
\end{abstract}

\section{Introduction}

In any attempt to relate the fundamental structure of a solid material to its useful mechanical and physical properties, one is forced to recognize three basic levels of organization. At the smallest level, beginning at about $10^{-8} \mathrm{~cm}$, atoms are organized into crystals of varying regularity and order, which may or may not contain molecular entities, and which usually incorporate imperfections such as vacancies, dislocations, and various larger defects. The properties of such individual crystals can be quantitatively determined by numerous measurements in the realm of physics, but frequently bear little direct relation to the gross properties of useful aggregates.

At the opposite end of the size scale, the properties of a useful piece of material are again quantitatively measured by the well standardized instruments of the engineer, and to some extent correlated with the gross chemical analysis and with semiquantitative parameters classed as the "material history." On the basis of such engineering properties, the material is incorporated into a structure or machine, within which it usually functions as expected.

Between these extreme levels of organization there falls the level of organization on the micro scale, in which dimensions will usually fall between $10^{-4}$ and $10^{-1} \mathrm{~cm}$. At this level, individual particles, usually crystals, of one chemical identity or "phase," are orientated and joined to other similar particles or, more frequently, dispersed between particles of other phases. In the resulting aggregate, the physi- cal and mechanical properties of the individual particles are combined in a very nonlinear manner to produce the engineering properties of the whole. A common analogy can be found in the fact that the strength of a masonry wall depends more on the skill with which the stones are cemented together than on the actual strength of either the stones or the cement. For inorganic materials, studies at this level fall into the closely parallel specialities of metallography and petrography, which use many techniques closely related to those of biological microscopy.

The traditional tool of the metallographer is the light microscope, which has in recent years been supplemented by the electron microscope for use on more minute structures, and the X-ray microscope for three dimensional studies. Elegant specialized methods have been developed for measuring some properties of individual particles; for example microspot spectrochemical analysis, microspot diffraction of X-rays or electrons, and micro-scale testing arrangements. Average crystal orientation data are obtained by X-ray diffraction and expressed in quantitative maps called "pole figures."

The use of the optical microscope for analysis of the phase systems in metallic materials offers certain specific advantages over the newer and more specialized methods. First, information is obtained on the shape and size distribution of the "grains" or phase particles, which information is very difficult to obtain by any other method. Second, optical examination includes a larger area than other 
methods, and thus more truly studies the whole material, as evidenced in part by the fact that the particles examined by specialized methods are usually first selected optically.

A cardinal rule of metallography requires that any recorded micrograph (photomicrograph) must be a true representation of the structural constituents of the whole material unless specifically stated to represent a special case. This assurance of validity can be achieved only by the critical examination of large areas of the specimen, or of several specimens, during which the metallographer accumulates a mental picture of an "average area," followed by the recording of one or several areas statistically representative of this average. An experienced metallographer, when examining a familiar structure or one in which the identity and nature of the phases is known, can deduce a good qualitative estimate of the properties of the material. With the aid of carefully prepared comparison standards, semiquantitative values can be obtained, but, unless numerous actual measurements are made on each micrograph, it is not feasible to obtain numerical data of a quality comparable with that of the specialized measurements on specific areas.

In most cases, the effort necessary to obtain a quantitative or mathematical description of the information displayed in a micrograph has been considered prohibitive. Thus while "there is no substitute for seeing" (Lucas), the information supplied by visual examination is under the best of circumstances only semiquantitative, and may sometimes prove to be misleading. The metallurgist has of necessity been forced to be satisfied with information not much better than a qualitative opinion based on accumulated experience or on visual comparison with a few laboriously measured "standard" micrographs.

Many aspects of the problems and methods of quantitative interpretation of micrographic information will be found reviewed in detail in the book "Quantitative Metallography" [1]. "The basic mathematical principles have long been known; for example, the Delesse Principle (1852) which states that the ratio of areas of phases on a random sliced surface is equal to the ratio of volumes of phases in the mass, and the methods of Rosiwal (1898) and Glagoleff (1933) which equate these volume ratios to the ratios of line intercept lengths and of point counts respectively.

The laws of the binomial distribution may be used to set minimum requirements for the amount of information to be processed to attain any desired potential degree of accuracy $[1,11]$. If one wishes to obtain a phase analysis with an accuracy comparable to the usual chemical analysis, one must process, irrespective of method used, nearly one million "binary bits" of information. Treating black and white micrographs with a useful resolution of 100 lines per inch or 40 lines per centimeter $(=10,000$ bits per in. ${ }^{2}$ or 1600 bits per $\left.\mathrm{cm}^{2}\right)$, an $8 \times 10 \mathrm{in}$.

1 Figures in brackets indicate the literature references at the end of this paper. (or $20 \times 25 \mathrm{~cm}$ ) print, totally analyzed, approximately fills the purely statistical requirement. A separate determination will be necessary to decide whether one such print, or an equal area of smaller prints, is in fact representative of the material. When an 8 step or 16 step grey scale can be usefully treated, the required area may be reduced by a factor of 3 or 4 ; or alternately, a full scale print may yield up to twice the accuracy of a black and white print of the same size.

Hand measurements at this level of detail imply an expenditure of time of the order of hundreds of hours per specimen. Much progress has been made in devising mechanical aids of several varieties which considerably reduce the labor requirement, but it has now become abundantly clear that the only practical tool for making high accuracy quantitative metallography an everyday process must be a digital computer system which directly accepts suitable photomicrographs, either in photographic or electrically recorded form, and prints out the desired statistical information. Such a program has been shown to be feasible, and has been described in detail in the chapter mentioned [1].

\section{Development of Computer Methods}

A number of laboratories have experimented with systems in which a computer "looks at" paper material originally designed for visual interpretation by the human eye [2], producing therefrom some numerical result. Some of these experiments have been closely related to metallographic measurement, but no general program suitable for micrographic analysis has been disclosed. It is believed that others are working along somewhat analogous lines.

Experiments generally using the same class of viewing and computing "hardware" fall in two distinct classes.

(A) Character recognition in which the computer is asked to "see" a hand-drawn or printed character and recognize the character by recording the equivalent code character. Such problems range from the recognition of numbers on bank checks to the translation of Russian script or Chinese ideographs into English.

(B) Picture interpretation; in which the visual material might be

1. Aerial or satellite photographs of the nature of a map or weather pattern.

2. Astronomical photographs.

3. Drawings, as for example, organic chemistry structure diagrams.

4. Photomicrographs, mainly

(a) Metallographic,

(b) Biological,

(c) Petrographic.

In all of these cases, the computer may be asked to state the frequency, size, location, or total occurrence (area) of one or more classes of objects ("blobs") which can be recognized by some topological rule. In general, program systems developed for any problem in Class B have some application 
to all of the problems in this group, but programs are not interchangeable with the A problems.

The National Bureau of Standards experiments on picture interpretation problems were initiated in 1956 by Kirsch, Cahn, Ray, and Urban [2], using the SEAC (Standards Electronic Automatic Computer) and translating black and white pictures into binary machine data by means of the scanner SADIE (Scanning Analogue to Digital Input Equipment) shown in figure 1. A cathode ray tube display of the picture in the SEAC memory was added in 1957. The first experiments were directed toward diagram recognition problems related to the Patent Office "HAYSTAQ" literature searching program, but experiments have also been conducted with star photographs and in the mapping field. A few typical metallurgical micrographs were processed for area at this time.

During 1958, R. B. Thomas, with G. H. Urban and L. C. Ray, compiled a "library" of routines, STRIP-2 (Standard Taped Routines for Image Processing) generally useful for all problems in the picture interpretation class. These routines are supplied to the computer from a magnetic sound tape, and are commanded in any desired combination by typing in seven-letter code words in shorthand English. This "library" has recently been augmented by the addition of two routines specifically composed for metallographic purposes. Additional programs are being composed to complete the statistical analysis of metallographic grain size distributions.

The present size limitation of "SADIE" (17.64 $\mathrm{cm}^{2}$ or approximately $3 \mathrm{in.}^{2}$ ) and the speed and memory limitations of SEAC limit present experiments to an accuracy much lower than that eventually desired. As a consequence of this, the present experiments serve primarily to develop logic which

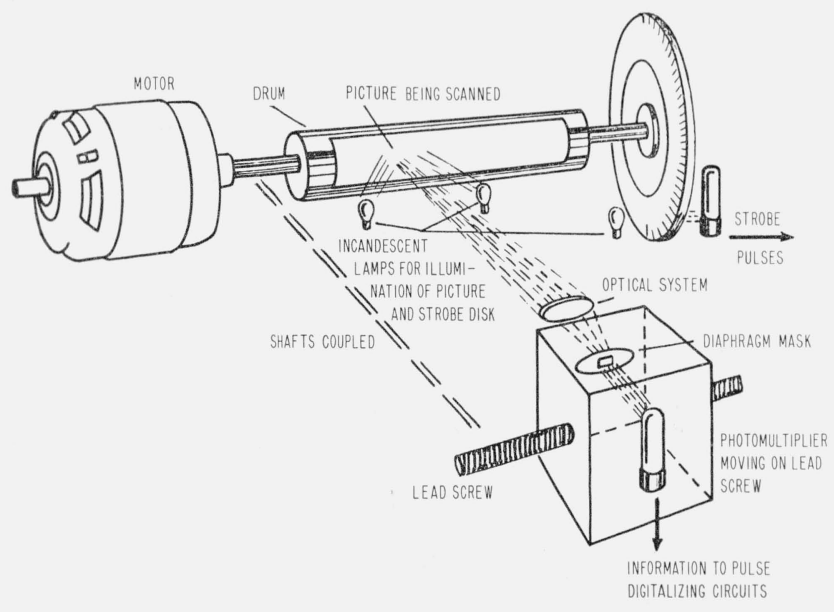

Figure 1. "SADIE" (Scanning Analogue to Digital Input Equipment) by which a picture is inserted into the computer memory. will shortly be translated for use on the new NBS computer, PILOT, where a combination of more powerful logical operations, much faster operation, and greatly expanded memory is expected to permit processing 80 in. $^{2}\left(500 \mathrm{~cm}^{2}\right)$ pictures in less time than is now required for the small sections on SEAC. Input equipment giving resolutions up to 80 lines per centimeter, areas up to $500 \mathrm{~cm}^{2}$ and an eight step grey scale is under construction for use with PILO'T, or alternately with a commercial computer when appropriate.

A future version of the system is anticipated to include a directly connected reader, composed of matrices of solid state photoluminescent and photosensitive elements, whereby a transparency (as a micrographic negative) will serve directly as the primary image memory and further reduce the machine time required for picture processing. Alternately, encoded picture tapes can be prepared on a slow mechanical scanner, or on a scanning microscope, and the tape supplied to the computer in place of the original picture.

\section{Elements of Computer Processing Programs}

SEAC is a three address computer operating at a bit-rate of one megacycle, in serial processing mode, with a memory capacity of 2,048 words. The average computation rate is somewhat over $1,000 \mathrm{com}-$ plete operations per second. The SEAC word consists of a string of 48 binary bits, of which the first 3 are dummies for machine control and the last is the sign; thus leaving 44 bits of actual information. This word may be interpreted in 5 ways:

1. A binary number of 44 places.

2. 44 independent Boolean statements.

3. A hexadecimal number $(0,1-9, \mathrm{~A}-\mathrm{F})$, of 11 places, each using 4 bits.

4. An alpha-numeric word of 7 letters, each using 6 bits.

5. An order, normally entered in hexadecimal, but actually interpreted as five independent binary numbers. Since the word interpretation is optional, an order can be treated as any other number, and thus incremented by addition to operate in succession on all, or on a selected portion, of the words in any specified block of the memory.

The logical ability is limited to 16 basic orders, viz:

Four operational-Read, Write (or "Dump"), Rewind source, and "File."

Six basic arithmetic-Add, Subtract, Multiply (major and minor portions of product) and Divide.

Three logical choices of program route by comparing or equating specified numbers.

One boolean operation-"And."

One pseudo-boolean operation- "Logical transfer."

One lateral displacement of word - "Shift."

The ability of SEAC to perform picture interpretation lies in the existence of the last three orders listed. Through the "Boolean And," 44 bit sections 
of two different images can be compared to produce a word showing only those spots where the images match or agree. The Logical Transfer order is a peculiar but powerful operation which may be likened to silk screen printing, or to the simultaneous printing of two negatives on to a single sheet of photographic paper. The information (1's and 0's) in Boolean word $\alpha$ is projected through the 1's in Boolean word $\beta$ to be copied into Boolean word $\gamma$, which at the same time is unchanged where the mask word, $\beta$, shows zeros. The equivalent Boolean function is: $\gamma^{1}=(\beta$ and $\alpha)$ or (not $\beta$ and $\left.\gamma\right)$. Thus, projecting an $\alpha$ of 44 zeros through a word $\beta$ which is part of a picture, into a $\gamma$, which is originally 44 ones, produces the complement (photographic reversal) of the image $\beta$. In another application, an $\alpha$ word from the original picture may be projected through a $\beta$ word which comes from a copy image, containing some small portion of a single grain, to make a new copy. If $\beta$ masks are obtained by shifting operations, using successively the eight adjacent image points of a square array, the copy will be enlarged by one ring of image points, but cannot acquire points absent from the original, and cannot grow through a boundary line of zeros. By many repetitions of this controlled copying, the image of some single "blob"-for example, a metallurgical grain - can be separately copied out - or transferred to a second image storage which is otherwise blank, and there measured in any desired manner.

By appropriate combinations of these elementary orders into routines varying in length from a few dozen to a few hundred order words, including instructions to apply the series in turn to each word of the entire picture, nearly any rigorously deined alteration or analysis of the picture can be accomplished.

\section{Present Operational Program}

To allow convenient use of computer operations for such purposes as quantitative metallography, it is first necessary to devise a series of specific routines, each of which will accomplish some specific and useful operation on a picture. Second, it is necessary to arrange that the operator can, in some simple manner, command the performance of specific selected routines whenever these are useful to the problem in hand.

This is accomplished by first feeding a "master routine" into a small part of the computer memory. The function of the master routine is to cause the machine to ask for a list of instructions, (which are in the form of English words); to store these, and then to carry them out in the listed sequence. To perform an instruction, the computer iirst searches along the order tape until it finds the matching title, then reads in the routine of detailed orders, and finally executes this set of orders. Thus, by typing in a few words in "English," the operator will cause the machine to read in and to execute some thousands of specific orders in the machine language.
For routine use, the selected list of instructions can itself be prepared in advance as on punched paper tape -and simply fed into a reading unit of the computer.

The present experiments are being performed with a specific "library" of routines, "STRTP-2B." As originally put into service in January 1959 (superseding less complete libraries) STRIP-2 had the capabilities shown in table 1 . The original capabilities include all the necessary manipulations to put a picture into the computer, select a portion (as one phase) of the picture, perform minor repairs or corrections, determine the area of the phase and count the number of particles shown. This list is adequate to perform elementary forms of quantitative metallography, such as to treat cases where the particles can be considered spherical.

In addition to the functions originally available, the following new analytical functions were composed during 1961.

(5c) LINE-This operation performs a complete lineal analysis for both image and background separately; treating the image as if it were wrapped into a cylinder. Histograms of line lengths, by $\sqrt{2}$ class increments, are generated together with statistical summaries of the histograms.

(5d) "BLTR"-Blob Transfer and Record: This operation abstracts one blob (or grain) at a time from the image, measures it, enumerates it, and states its area, location in the image and dimensions. This is a faster and more complete form of the BLOB operation, primarily designed for determining grain size distributions. Grains cut by the border are identified by the location parameters.

\section{TABLE 1. Original functional capabilities of "STRIP-2"}

\section{(1) Input-Output functions:}

(a) SCAN - Operates the device SADIE and supplies the computer with one picture $44 \mathrm{~mm}^{2}$ recorded as 704 words. This is stored in either of 2 Image Spaces, "A" or "B" in the memory. Black picture objects are recorded as computer 1's, which will be displayed white on the output scope. A blank border, $1 \mathrm{~mm}$ (4 bits) wide is masked onto the picture. The gross picture area is 30976 bits and the net usable area inside the border is 28224 bits (17.64 $\mathrm{cm}^{2}$ or approximately $2.82 \mathrm{in.}^{2}$ ).

(b) READ - A previously scanned and electrically recorded picture is read back into the machine.

(c) DISPLAY - One image is exhibited on the cathode ray (TV) tube.

(d) DUMP - An image in the machine is electrically recorded on wire or tape.

(e) PUNCH-An image is recorded as coded characters on a paper tape (can be used to transfer the image to a different computer).

(2) Program sequencing functions:

(a) I'TERATION (Repeat series of operations).

(b) TRAC (Transfer to different operation on "Clear 0" signal from Console).

(c) TRAZ (Transfer Operation if Area=Zero).

(d) TRA (Transfer Operation, Unconditional). 
These operations permit recycling the machine through selected portions of the listed orders, or repeating the entire list on successive pictures without retyping the list of orders.

(3) Picture shifting functions:

(a) ROTATE-Picture is turned 90 or $180 \mathrm{deg}$, as may be necessary for a directional interpretation.

(b) COPY - One image is duplicated in the $2 \mathrm{~d}$ image space, permitting further transformation without loss of the original.

(c) SWAP-Two images are interchanged.

(4) Image modification functions:

(a) COMPLEMEN'T-Photographic Reversal.

(b) AND - Shows image features (ones) common to each of 2 images.

(c) OR - Combines features (ones) existing in either of 2 images.

(d) M2S-Modulo-2 Superposition: Shows features (ones) existing in either one of 2 images but not in both.

(e) ERASE-Destroys one image.

(f) NOISE-Inserts a specified proportion of "dust" similar to "snow" in a television program. This permits experiments on how to clean a dirty image.

(g) CUSTER - This operation wipes out the internal area of each image spot (or blob) saving. only the outline. One application is to use this information to estimate the grain boundary area of the phase represented in the image.

(h) BITOP - This is a general Boolean operation on one entire image, producing a new image in which the nature of each new image point $C^{\prime}$ is specified by any desired Boolean function of the original point value $C$, and of the values of the eight nearest neighbors $A, B, D, E$, and $1,2,3,4$.

\begin{tabular}{|l|c|c|}
\hline 1 & $A$ & 2 \\
\hline$B$ & $C$ & $D$ \\
\hline 3 & $E$ & 4 \\
\hline Point array for BITOP \\
\hline
\end{tabular}

Boolean functions are written: $A B$ ( $A$ and $B$ ); $A+B(A$ or $B) ; A-B(A$ and not $B)$ etc.

Some of the useful BITOP functions which may be written are:

"Etch": $C^{\prime}=A B C D 1234$ which will discard the border line (custer) and save the solid center of each blob. It has been used (ref. 1) to separate and correctly count powder particles which were clustered in a micrograph.

"Plate": $C^{\prime}=A+B+C+D+E+1+2+3+4$ will restore the original image after etching, except that blobs originally less than 9 bits in area, or lines less than 3 bits thick will have vanished.

"Clean": $C^{\prime}=C+A B C D 1234$ will eliminate all single blank points existing within an image.
More complex BITOP functions could be used to erase scratches which might appear in a micrograph of a poorly polished specimen, or to repair small defects in the etching of grain boundaries.

\section{(5) Analytical functions:}

(a) AREA - This operation counts the number of image points in the image. Division of area by the appropriate total (30976 or 28224) gives the percentage of the phase represented by the image.

(b) BLOB - This operation enumerates the individual separate areas, or blobs, (which in the metallographic case would usually be the grains) and states the area of each. Tabulation of these data will give a grain size distribution.

\section{Experimental Illustrations}

In the previously mentioned report [1], illustrations of computer interpretation are given for three types of cases. The central section of one of the ASTM grain size charts was measured, with results in close agreement with the stated value. A group of powder particles, containing a few clusters, was separated by use of the "Etch" Bitop function, and the particles counted and measured. A three-phase dendritic structure was analyzed for the area of the three phases, using scans at two levels of grey sensitivity, and the M2S function to obtain an image of the grey phase alone.

Recently, analyses have been made of the numbers and sizes of carbide particles found in aging gage block steels. These will be reported on a future occasion when they can be related to the changes which occur in such blocks. Analyses have also been made of a number of graphitic type structures of interest in establishing standards for cast iron. [14]

There is currently very widespread interest and activity concerned with the superconductor material $\mathrm{Nb}_{3} \mathrm{Sn}$. Since the current knowledge of the physical metallurgy of this material can be increased by quantitative metallographic determinations within the accuracy range obtainable from the present small picture format, experiments are at present being conducted with micrographs of this material. The structure of this material is typically so complex that simple relationships between various geometrical parameters are not applicable, hence each desired parameter must be measured directly.

\section{Niobium-Tin Superconductor}

Magnetic fields more powerful than can in practice be obtained in any other manner can be created by the use of solenoids of superconducting wire operated at liquid helium temperature $[3,4]$. Such fields have many potential applications, including nuclear fusion devices [5].

Niobium and tin are both elemental superconductors, and this property occurs in at least two of the intermediate phases of the alloy system. Within the past few years, considerable interest has been shown in the compound $\mathrm{Nb}_{3} \mathrm{Sn}$ for its 
possible application to the fabrication of superconducting solenoids. Unfortunately, $\mathrm{Nb}_{3} \mathrm{Sn}$ is very brittle and can not be processed by normal metallurgical methods. If, however, a stoichiometric mixture of $\mathrm{Nb}$ and $\mathrm{Sn}$ powders is compressed within a niobium tube, the duplex tube containing the moderately ductile mixture can be cold worked to wire, wound into coils, and finally the core converted to the $\mathrm{Nb}_{3} \mathrm{Sn}$ phase by appropriate heat treatment.

However, it has been found that wires prepared in this manner may have properties which differ significantly from specimen to specimen, particularly with respect to the retention of superconductivity in high magnetic fields or with high current densities. It is presently thought that the differences in the behavior of various specimens may reflect differences in the form and distribution of the $\mathrm{Nb}_{3} \mathrm{Sn}$ phase which is produced by the heat treatment accorded the mechanical mixture of $\mathrm{Nb}$ and $\mathrm{Sn}$ powders in the niobium sheath.

\section{Superconductor "Quality"}

In the absence of an agreed upon quantitative measure of the concept of superconductor quality, it is necessary to establish some working hypothesis covering the factors which may be involved. Given a superconducting material, the superconducting state can be destroyed either by an increase in temperature, a high magnetic field, or by excessive current. These three influences cooperate in a complex manner, and a high test value for one factor does not necessarily guarantee an equally high value for the other two.

Thus, in practice, a high quality superconductor is one which, at the intended service temperature, successfully resists a high magnetic field and simultaneously carries a current sufficient to establish this field. ${ }^{2}$

Metallurgical reasoning toward improving superconductor quality may emphasize the current carrying factor as appearing to be somewhat less obscure than the others. Subject to certain limitations, those metallurgical changes which would increase the normal conductivity of a specific material may be expected to be of at least some benefit to its superconducting quality. However, at least two distinct types of superconductor materials are recognized. In the "ideal" or "soft" superconductor (viz, pure tin) the superconductive current appears to be largely confined to the surface. In a "hard" superconductor, such as niobium-tin, the critical current appears to be approximately proportional to cross-sectional area, hence the superconductive current appears to flow in the volume. A possible

\footnotetext{
2 If alternating current or pulsed applications are planned [5], additional factors may be involved in the concept of quality. Thus it may be required that the superconducting material must not introduce sources of non-ohmic impedances viz: inductances, capacitances, or rectifying junctions. It has been shown [6] that at least one porous, or distended, alloy structure $\left(\mathrm{Pd}_{-} \mathrm{H}_{2}\right)$ has capacitive that at least one porous, or distended, alloy structure $\left(\mathrm{Pd}_{-}-\mathrm{H}_{2}\right)$ has capacitive
properties. In the presence of particles of several phases, the possibility of properties. In the presence of particles of several phases, the possibility of "microelectronic" effects may further restrict the range of acceptable metallographic structures.
}

intermediate condition is one in which the current follows "internal surfaces" whose nature has not yet been definitely specified.

The most obvious metallurgical factors which may bear on the performance of various $\mathrm{Nb}_{3} \mathrm{Sn}$ wires fabricated as previously indicated are (1) the mean, or the minimum, effective area of superconducting phase in a cross section perpendicular to the current flow, and (2) continuity of superconducting phase along the length of the wire. ${ }^{3}$ An additional factor which might be involved in determining the overall performance of a wire is the anisotropy of grain shape. In particular, long or fibrous grains alined along the wire axis might be a desirable structure.

Other factors relating to the stoichiometry and lattice perfection within individual orains are probably also quite important. However, these factors are best investigated by diffraction methods and will not be further considered at this time. Factors 1 and 2 and the question of grain shape and orientation are matters which can be evaluated by quantitative metallography.

Methods will be illustrated for obtaining measurements of the volume fraction of the superconducting phase and of its continuity, of the mechanical mean free path, and of the sizes and shapes of the particles of the various phases present.

\section{Niobium-Tin Alloy System}

The specimens presently under investigation by quantitative metallography are part of a series of diffusion specimens and reacted powder mixtures which have been under investigation by a number of methods in an effort to establish the phase diagram of the $\mathrm{Nb}-\mathrm{Sn}$ system and to determine the most effective method of preparing the $\mathrm{Nb}_{3} \mathrm{Sn}$ phase [8].

Specimens are polished normally and are then anodized, without etching, by the method of M. L. Picklesimer [9] to develop characteristic colors on each of the phases.

The colors produced on different metallographic constituents vary somewhat with the degree of anodization, and can be deliberately varied to aid in distinguishing phase areas. On the basis of microspot spectrochemical analyses of characteristic areas, the constituents in the microstructures have been tentatively identified [8] as shown in table 2 .

TABLE 2.-Tenative identification of meallographic constituents in Niobium-Tin alloys

(1) Niobium metal, which may contain up to about 10 percent tin in solid solution. The charac-

3 Values for the electronic mean free path are commonly computed from conductivity data, and may run from the order of $100 \mathrm{~A}$ at room temperature to the order of a millimeter or more in good conductors near absolute zero. The high value at low temperature, where the effect of thermal vibrations has vanished, is referred to as "residual electronic mean free path" $\left(L_{r}\right)$. The "reciprocal residual mean free path" $\left(1 / L_{r}\right)$ is the average number of interruptions per centiresidual mean fro path (1/ meter of electron travel due to residual impurities and mechanical imperfections. Hagedorn [7] reports that $L_{r}$ corresponds to the observed grain size in superconducting high purity tin films, and proposes that the superconducting transition temperature of poor films is lowered by an amount $\Delta T_{c}$, proportional to $\left(1 / L_{r}\right)$. The number of interruptions here considered should be the sum of the
microscale interruptions measured by the mechanical mean free path and of the atomic scale interruptions due to impurities and crystal imperfections. 
teristic color is in the light blue range, viz: "Light Beryl Blue" in the Maerz Dictionary of Color [10].

(2) Phase, nominally $\mathrm{Nb}_{4} \mathrm{Sn}$, with a composition range of around 6 atomic percent. This phase is believed to melt congruently not far below the melting point of $\mathrm{Nb}$ metal. The color is consistently a more brilliant blue than Nb; "Calamine Blue." This phase has been reported to be a superconductor of moderately good quality.

(3) Phase of nominal composition $\mathrm{Nb}_{3} \mathrm{Sn}$, probably of fixed composition. This phase is generally believed to be one of the best superconductors now known. The characteristic color is darker than the $\mathrm{Nb}_{4} \mathrm{Sn}$, and more reddish, ranging from "Orient" (blue) to magenta (process red) according to anodizing treatment. This phase is presently thought to decompose by a peritectoid reaction (to $\mathrm{Nb}_{4} \mathrm{Sn}$ $\left.+\mathrm{Nb}_{2} \mathrm{Sn}_{3}\right)$ around $730{ }^{\circ} \mathrm{C}$.

(4) Phase of nominal composition $\mathrm{Nb}_{2} \mathrm{Sn}$, which is characteristically more red than $\mathrm{Nb}_{3} \mathrm{Sn}$, viz: "Purple Aster" when $\mathrm{Nb}_{3} \mathrm{Sn}$ is "Orient." The phase has been tentatively equated with areas which are greenish when $\mathrm{Nb}_{3} \mathrm{Sn}$ is anodized to magenta. This phase is presently believed to decompose by a peritectoid reaction (to $\mathrm{Nb}_{3} \mathrm{Sn}+\mathrm{Nb}_{2} \mathrm{Sn}_{3}$ ) around $690{ }^{\circ} \mathrm{C}$.

(5) Phase of nominal composition $\mathrm{Nb}_{2} \mathrm{Sn}_{3}$, which is very dense and brittle. The color range is in the brownish yellows, viz, "Burnt Sienna" to yellow. This phase appears to decompose by peritectic reaction to $\mathrm{Nb}_{4} \mathrm{Sn}$ and liquid at about $863{ }^{\circ} \mathrm{C}$. The formation of this structure has been associated with the formation of porosity.

(6) Sn or quenched supersaturated solution of $\mathrm{Nb}$ in Sn. The tin side of the system appears to be occupied by a low melting eutectic mixture. The high tin material is more yellow than any of the other constituents, viz: "Chrome Yellow" or golden.

(7) Impurities: The impurity most often recognized is Salmon Pink in color and may perhaps be niobium nitride.

(8) Porosity: Reacted powder mixtures characteristically show considerable porosity, even when the powders were fully compacted. The amount of this porosity generally increases with the amount of tin incorporated, and is high for mixtures of the $\mathrm{Nb}_{2} \mathrm{Sn}_{3}$ ratio. The blackness of the pores is partly obscured by reflections of yellow or green light from high tin material coating their inner surfaces. Pores deliberately filled with acrylic plastic are white under polarized light.

\section{Low Quality $\mathrm{Nb}_{3} \mathrm{Sn}$ Wire}

If high quality superconducting devices are to be manufactured on a reliable basis, it will be necessary to relate the superconducting quality of $\mathrm{Nb}_{3} \mathrm{Sn}$ materials to the details of the complex phase structures which may be formed under various fabricating treatments. To this end, the balance of this report is devoted to a detailed quantitative analysis of a microstructure which is believed to represent a quality somewhat below an acceptable level, and thus should illustrate the types of defects which should be eliminated.

An original color micrograph, of which a general print is shown in figure 2, was supplied by Dr. M. L. Picklesimer of the Oak Ridge National Laboratory. This comes from a section of commercial core wire which was given only a minimum heat treatment of 2 hours at $1,000{ }^{\circ} \mathrm{C}$, and was selected as a low quality area by virtue of higher-than-usual electrical resistance at room temperature. Other sections, more completely heat-treated, had normal quality for the period (July 1961).

The color transparency was copied in the photographic laboratory to produce 4 color-separation negatives similar to ones which would normally be made for ink reproduction. From these, highcontrast black-and-white prints were made for the computer input. These prints were then cut in sets of matching areas to produce three separate series for computer analysis, as shown in figure 3 . By comparison with specimens made for the diagram study, and with other transparencies supplied by Dr. Picklesimer, the separations are judged to contain the following materials:

\section{Black - holes or voids}

Blue (actually cyan or blue-green)-Niobium with some tin in solid solution, together with a lesser amount of $\mathrm{Nb}_{4} \mathrm{Sn}$ not clearly seen in this particular micrograph.

Yellow- $\mathrm{Nb}_{2} \mathrm{Sn}_{3}$

Magenta (purple or "Process Red") - The presumed superconducting phase $\mathrm{Nb}_{3} \mathrm{Sn}$.

The magenta area of the original contained numerous "dots" of various colors, not all of which were successfully reproduced in the black and yellow separations. It is believed that a small amount of extraneous material, mainly $\mathrm{Nb}_{2} \mathrm{Sn}$, has been included in the magenta separation.

In selecting the three areas to be shown to the computer, sections 1 and 2 were logical cuts of the left and right portions of the original, while section 3 was deliberately chosen to try to make the material look as good as possible. This allowed a statistical evaluation of the possible effect on the computer results of nonobjectivity on the part of the metallographer. It may be seen, in the results to follow, that this attempt to deceive the computer was statistically unsuccessful; hence the results from the three cuts have been combined in the total analyses.

The prints shown were analyzed on a number of occasions during the perfection of the LINE and BLTR routines with results in overall agreement with each other. However, results are reported only for analyses obtained after the routines were fully corrected. The total (SEAC) computer time used in obtaining the reported data for 12 pictures was $129 \mathrm{~min}$.

\section{Area and Material Balance}

The area values obtained by the AREA order, and duplicated exactly in the LINE analyses are shown 


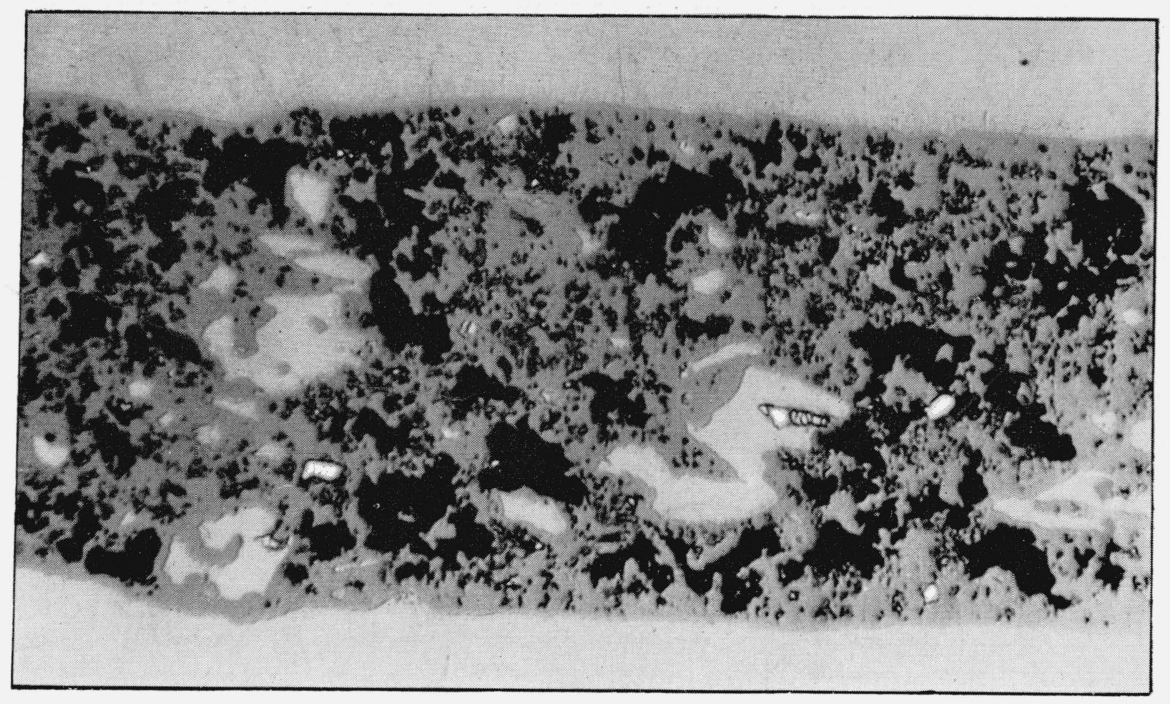

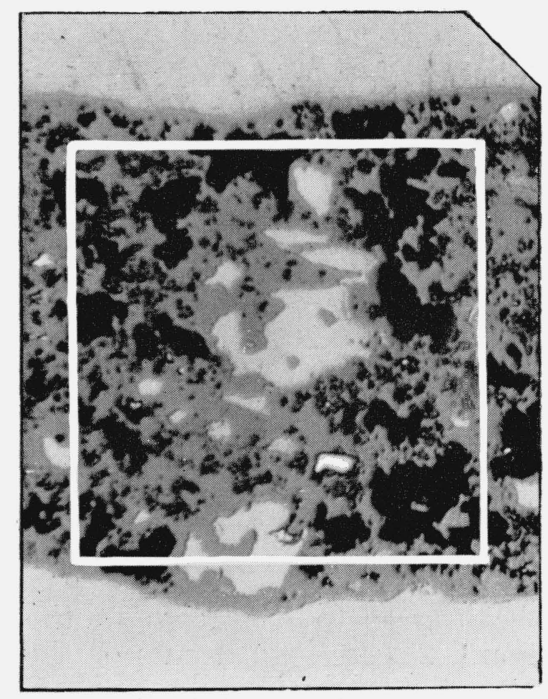

a

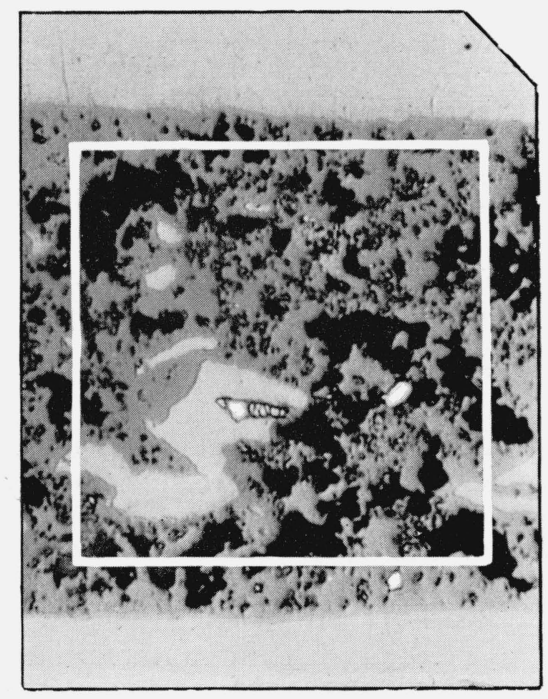

b

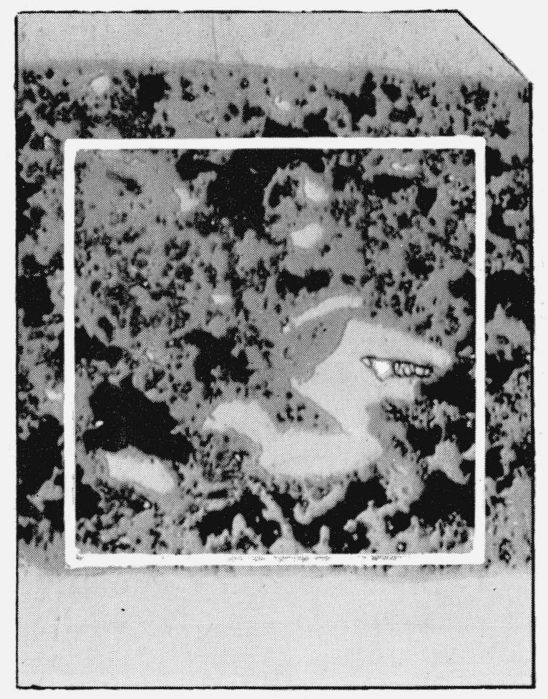

C

Figure 2. General view of low quality $\mathrm{Nb}_{3} \mathrm{Sn}$ core wire.

Grey: $\mathrm{Nb}_{3} \mathrm{Sn}$ phase (magenta)

Light: $\mathrm{Nb}$ solid solution $+\mathrm{Nb}_{4} \mathrm{Sn}$ (blue)

Light: $\mathrm{Nb}_{2} \mathrm{Sn}_{3}$ phase (yellow)

From Color Micrograph \#CY $468(250 \mathrm{X})$, courtesy of

Dr. M. L. Picklesimer (Oak Ridge National Laboratory)

Areas of micrograph used for computer analysis
$\begin{array}{lll}\text { (a) Cut } 1 & \text { (b) Cut } 2 & \text { (c) Cut } 3\end{array}$ 


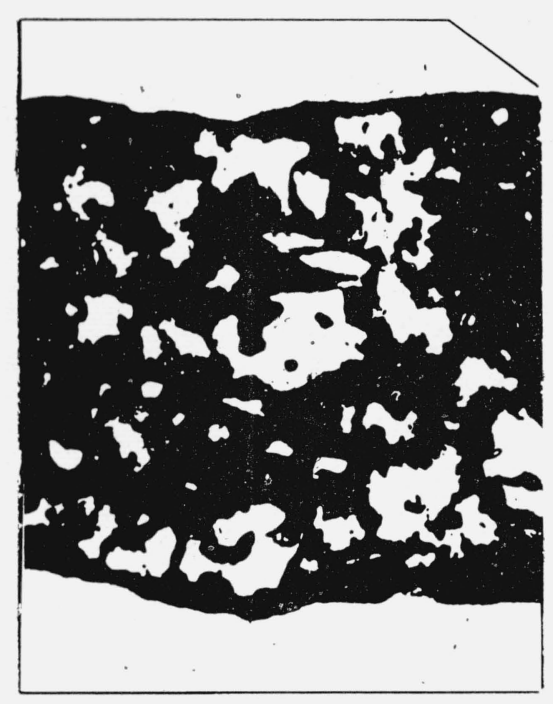

a

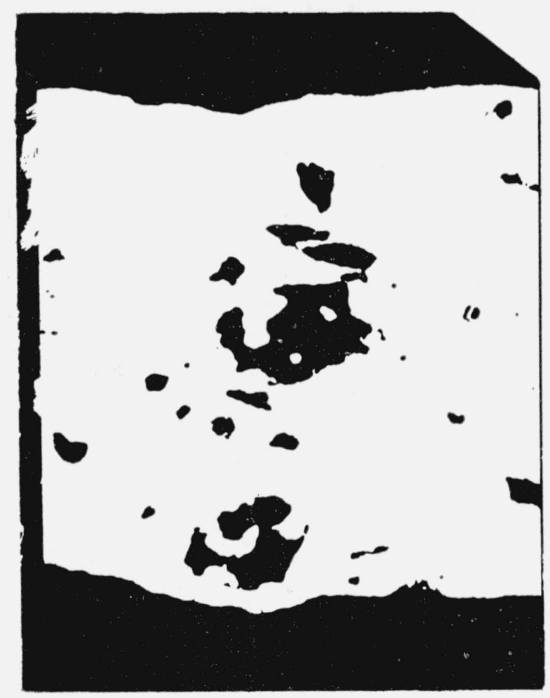

d

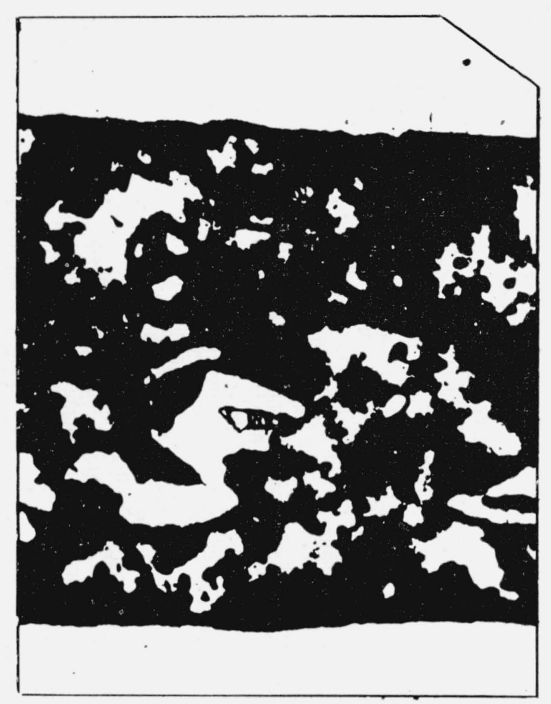

b

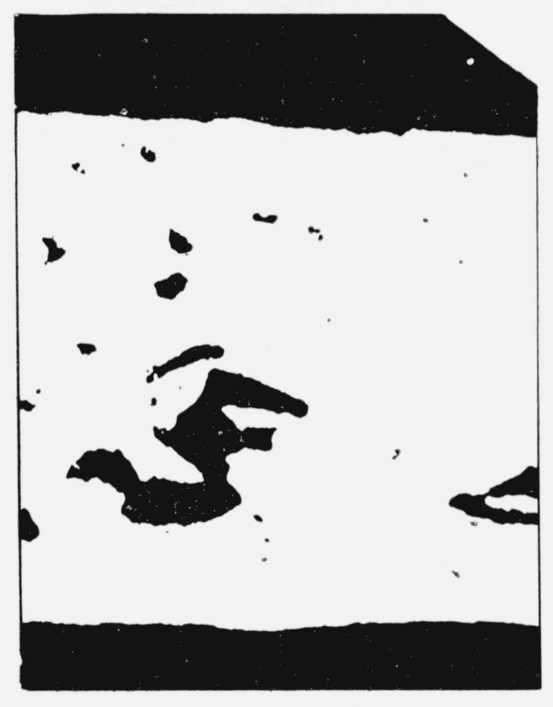

e
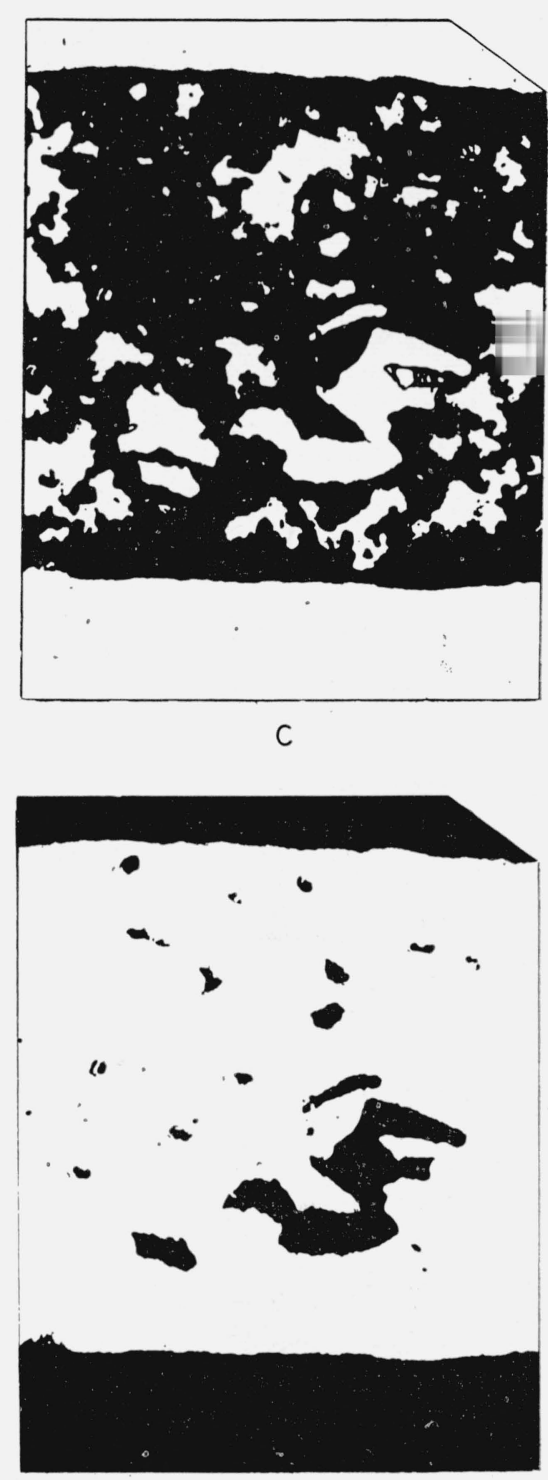

f

FIGURE 3. Micrographs used for computer analysis.

Magenta separations $\left(\mathrm{Nb}_{3} \mathrm{Sn}\right.$ phase) of the same color micrograph $\begin{array}{llll}\text { Blue separations ( } \mathrm{Nb}+\mathrm{Nb}_{4} \mathrm{Sn} \text { ) of the same color micrograph } & \text { (d) Cut } 1 & \text { (e) Cut } 2 & \text { (f) Cut } 3\end{array}$ 


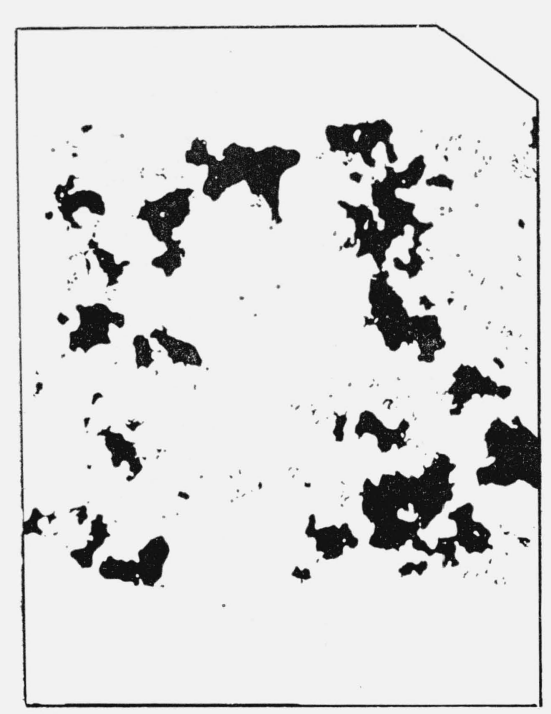

g

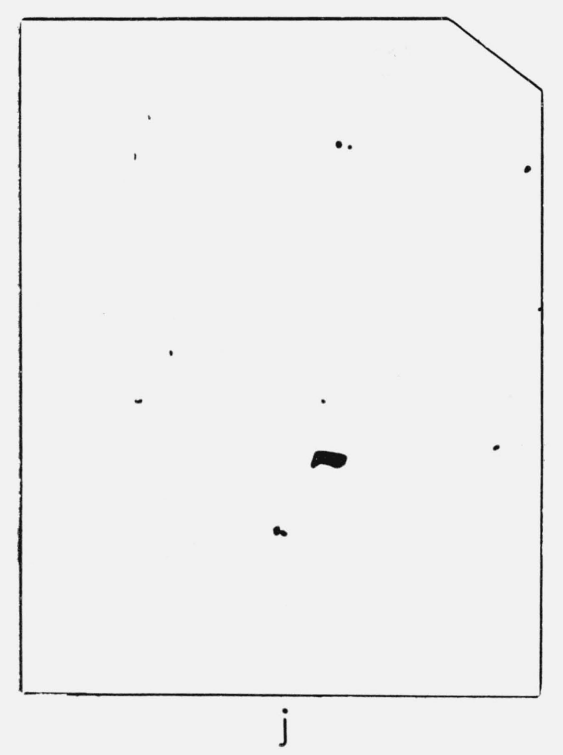

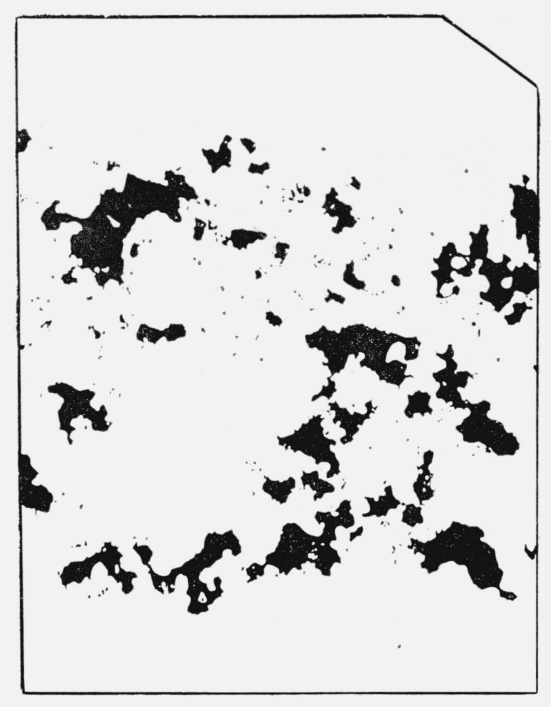

h

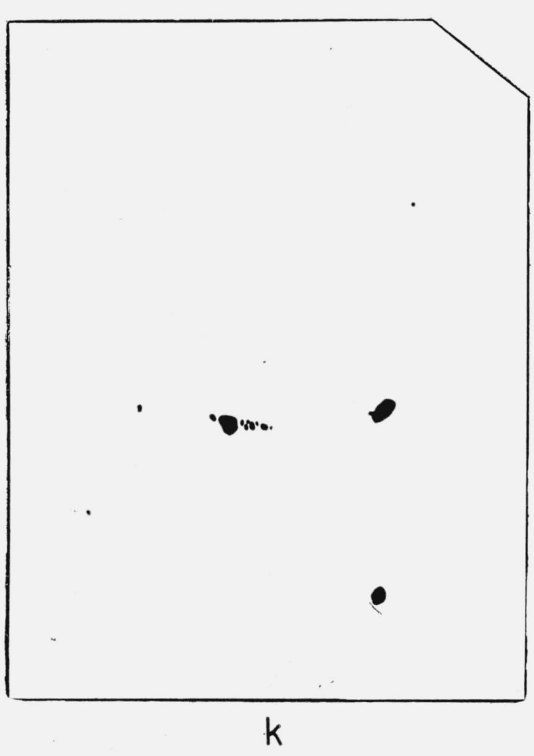

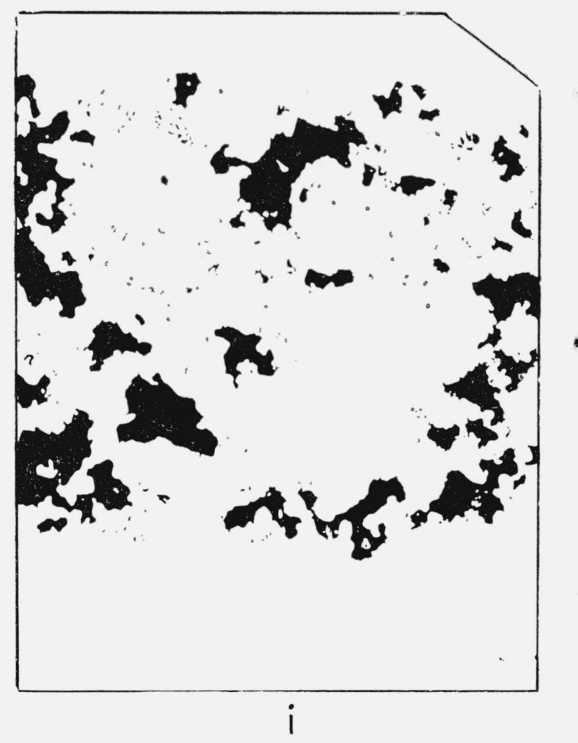

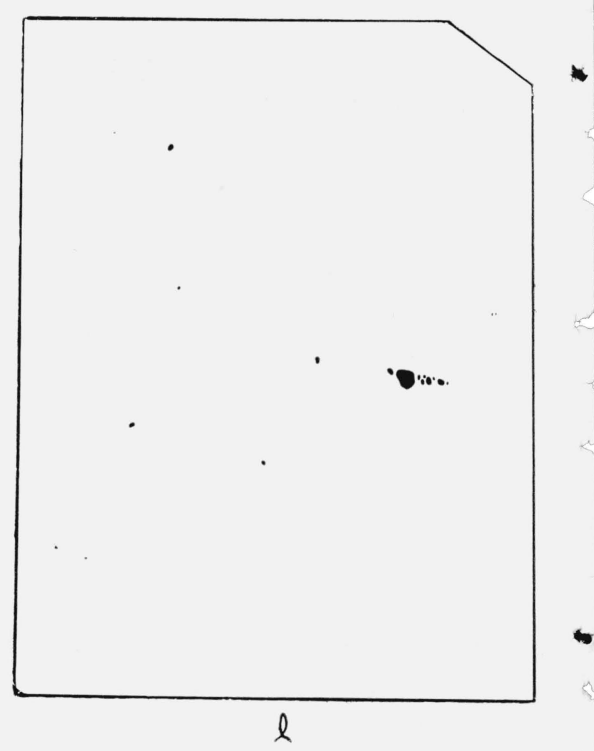

FigURE 3. Micrographs used for computer analysis - Continued

$\begin{array}{llll}\text { Black separations (Voids) of same (Con't) } & \text { (i) Cut } 3\end{array}$

Yellow separations $\left(\mathrm{Nb}_{2} \mathrm{Sn}_{3}\right)$ of the same

$\begin{array}{lll}\text { (j) Cut } 1 & \text { (k) Cut } 2 & \text { (1) Cut } 3\end{array}$ 
in table 3. Due to the tendency of high contrast prints to show slight enlargement of black areas, together with a photocell setting which probably slightly favored image detection, the four prints of a set add up to slightly more than the theoretical area of 28224 units. The actual totals, rather than the theoretical values, are therefore used to obtain the percentage by volume of the constituents, on the assumption that the reading error may be proportional to the area actually read. As the micrograph is at $\times 250$, and 1 computer unit $=0.25 \mathrm{~mm}$ on the print, one computer unit is $0.001 \mathrm{~mm}(1 \mu)$ in actual length and $10^{-6} \mathrm{~mm}^{2}$ in actual area.

TABLE 3. Areas and material balance in low quality $\mathrm{Nb}_{3} \mathrm{Sn}$ wire specimen

1 unit $=0.000001 \mathrm{~mm}^{2}$

\begin{tabular}{|c|c|c|c|c|}
\hline Item & Cut 1 & Cut 2 & Cut 3 & Total \\
\hline $\begin{array}{l}\text { Magenta. } \\
\text { Blue area... } \\
\text { Black area... } \\
\text { Yellow area....... }\end{array}$ & $\begin{array}{r}20055 \\
3327 \\
5878 \\
306\end{array}$ & $\begin{array}{r}21082 \\
3014 \\
4948 \\
301\end{array}$ & $\begin{array}{r}21349 \\
3235 \\
5010 \\
293\end{array}$ & $\begin{array}{r}62486 \\
9576 \\
15836 \\
900\end{array}$ \\
\hline $\begin{array}{l}\text { Total area } \\
\text { Ideal total }\end{array}$ & $\begin{array}{l}29566 \\
28224\end{array}$ & $\begin{array}{l}29345 \\
28224\end{array}$ & $\begin{array}{l}29887 \\
28224\end{array}$ & $\begin{array}{l}88798 \\
84672\end{array}$ \\
\hline$\Sigma 4$ errors. & 1342 & 1121 & 1663 & 4126 \\
\hline
\end{tabular}

As percentage of total readings

\begin{tabular}{|c|c|c|c|c|}
\hline $\begin{array}{l}\Sigma 4 \text { reading errors. } \\
\text { Holes (black) }\end{array}$ & $\begin{array}{r}\% .54 \\
4.88\end{array}$ & $\begin{array}{r}3.82 \\
16.86\end{array}$ & $\begin{array}{r}\% .56 \\
16.76\end{array}$ & $\begin{array}{rr}\% & 4.65 \\
17.83\end{array}$ \\
\hline
\end{tabular}

Phases as percentage of total solid

\begin{tabular}{|c|c|c|c|c|}
\hline Solid area $\ldots \ldots$ & 23688 & 24397 & 24877 & 72962 \\
\hline Magent & $\%_{84.66}$ & $\%_{86.41}$ & $\%_{85.82}$ & ${ }^{\%}{ }_{85.64}$ \\
\hline Blue _................ & 14.05 & 12.35 & 13. 00 & 13. 12 \\
\hline Yellow_-_-_-_-_-_ & 1.29 & 1.23 & 1. 18 & 1. 23 \\
\hline
\end{tabular}

Material balance, assuming $\mathrm{Nb}_{3} \mathrm{Sn}$ mixture in original

\begin{tabular}{|c|c|c|c|c|c|c|c|c|}
\hline & $\mathrm{Nb}$ & Sn & $\mathrm{Nb}$ & Sn & $\mathrm{Nb}$ & $\mathrm{Sn}$ & $\mathrm{Nb}$ & $\mathrm{Sn}$ \\
\hline Original (at \%). & 75.00 & 25.00 & 75.00 & 25.00 & 75.00 & 25.00 & 75.00 & 25.00 \\
\hline Blue (at $10 \%$ Sn) ... & 12.64 & 1.41 & 11. 11 & 1. 24 & 11. 70 & 1. 30 & 11.81 & 1.31 \\
\hline $\mathrm{Nb}_{2} \mathrm{Sn}_{3},($ yellow) & 1. 03 & 1.55 & 0.98 & 1.48 & 0.94 & 1.42 & 0.98 & 1.4 \\
\hline Apparent magenta & 61.33 & 22.04 & 62.91 & 22.28 & 62.36 & 22.28 & 62.21 & 22.21 \\
\hline $\begin{array}{l}\text { Magenta, } \\
\text { normalized }\end{array}$ & 73.56 & 26.44 & 73.85 & 26.15 & 73.68 & 26.32 & 73.69 & 26. 31 \\
\hline
\end{tabular}

Assuming the statistics of the binomial distribution to be applicable to the measuring process used, one may expect [11] for a sample size of 28224 units, a standard deviation of about 74 units $(=0.26 \%$ of the gross) in estimating a value of about 21000 units, which would decrease to about 5 units ( $=0.02 \%$ of the gross) when measuring 1 percent of the area; that is a maximum error $(3 \sigma)$ of less than 1 percent on any area measurement. The discrepancies between the three cuts in table 3 are somewhat larger than predicted in this manner, except for the yellow phase which conforms exactly. The (RMS) average deviation of the 12 area readings from their respective averages is 366 units, or 1.30 percent. Thus the nonrepresentative nature of the small micrographs appears to introduce errors about four times as great as those inherent in the sample size itself. However, the table shows that cut 3 does not exhibit the greatest deviation from the mean in any of the four measurements, hence the attempt to deliberately select a statistically invalid area was unsuccessful.

It may be noted from the area values that the magenta area, presumably the desired superconductor, accounts for only about 70 percent of the total core area. Of the remainder, almost 60 percent is occupied by voids, with the balance being occupied by unreacted niobium (with some $\mathrm{Nb}_{4} \mathrm{Sn}$ ) except for about 1 percent occupied by high tin material $\left(\mathrm{Nb}_{2} \mathrm{Sn}_{3}\right){ }^{4}$

If it may be assumed that the original powder mixture was actually 75 atomic percent niobium and 25 percent tin, these materials may be allocated to the phases found, although the simple balance rule of a two phase system is not applicable here. To minimize the effect of errors, it is appropriate to assign the material first to the minor phases, and determine the apparent content of the major phase by difference. The densities of the phases are needed for an accurate evaluation. All intermediate phases apparently are denser than the mixed elements. As specimens consisting mainly of $\mathrm{Nb}_{2} \mathrm{Sn}_{3}$ show around 50 percent voids, the relative density of $\mathrm{Nb}_{2} \mathrm{Sn}_{3}$ is assumed to be 2 . The density of the blue material is assumed not to be significantly different from that of $\mathrm{Nb}_{3} \mathrm{Sn}$, for the present purpose. As the blue particles appear to include some $\mathrm{Nb}_{4} \mathrm{Sn}$, they are assumed to average somewhat higher in tin than the saturated niobium and assigned an arbitrary composition of 10 percent Sn.

On these assumptions, the magenta material appears to have a composition slightly above 26 atomic percent tin, and must be primarily $\mathrm{Nb}_{3} \mathrm{Sn}$. The data certainly do not justify assuming that this phase departs from the stoichiometric ratio, and the accuracy of the estimate probably does not demand an explanation of the discrepancy. Nevertheless, the magenta area is thought to contain a little $\mathrm{Nb}_{2} \mathrm{Sn}$, which could rise the average tin content by a fraction of 1 percent, and it appears entirely reasonable that the reacting mixture may have dissolved around 3 percent of niobium from the sheath material.

\section{Lineal Analysis}

The Lineal Analysis routine (LINE) makes a total lineal analysis of one computer image in one specific (Horizontal) direction which, in the present examples, is made the axis of the wire. The picture is treated as if wrapped into a vertical cylinder; that is, the edges are jumped so that a totally black image would be seen as one continuous helical line 28224

${ }^{4}$ Brittle Behavior of $\mathrm{Nb}_{3} \mathrm{Sn}$. Edelson and Baldwin [12] report that the tensile ductility of powder metallurgy copper alloys falls off rapidly as a function of the total volume fraction of holes and foreign particles, irrespective of the nature of these particles, their size, or the mean free path in the copper. More than 70 percent of the original ductility is lost at 5 volume percent noncopper, and nearly percent of the original ductility is lost at 5 volume percent noncopper, and nearly
all at 30 volume percent. As the ductility of pure Nb is of the same order as that all at 30 volume percent. As the ductility of pure $\mathrm{Nb}$ is of the same order as that
of copper, a core which contains only 70 percent $\mathrm{Nb}_{3} \mathrm{Sn}$ might be very brittle of copper, a core which contains only 70 percent $\mathrm{Nb}_{3} \mathrm{Sn}$ might be very brittle
purely as a result of its interrupted structure, without necessarily requiring that $\mathrm{Nb}_{3} \mathrm{Sn}$ would be brittle in pure form. 
units long. Each uninterrupted traverse in black (1's) or white (0's) is measured, added into the total (area), looked up in a class distribution table, and tallied as one occurrence of a line of the appropriate class.

A typical computer print-out is shown in table 4 , which gives the analysis for the magenta phase of cut 1 of the wire micrograph. In this print, the three lines following "LIST" are the instructions inserted by the operator, with all other printing done by the machine. The "CLEAR O" instructions from the machine to the operator represent options to record the table in either of the two number systems. Fractions of a computer unit are dropped in the mean free path (M.F.P.) values and the two standard deviations, but can be retrieved from the total lines, area, and variance values.

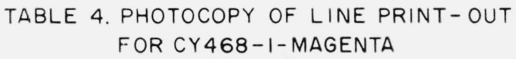

While particle area distributions can be deduced from lineal analyses, such operations require assumptions which would be invalid in the present case. Area distributions are obtained directly in the BLTR routine.

The significance of lineal analysis in the present case lies in the determination of a value for the mechanical mean free path in the superconducting phase in the axial direction. This value, of course, takes no cognizance of possible disturbances of regularity on the atomic scale, but as previously noted (footnote 3), the mechanical and electrical values of the mean free path may be expected to be similar for sufficiently pure materials at very low temperatures.

The line length class distributions for the three cuts of the magenta $\left(\mathrm{Nb}_{3} \mathrm{Sn}\right)$ pictures are plotted in figure 4. The bars of this histogram have been

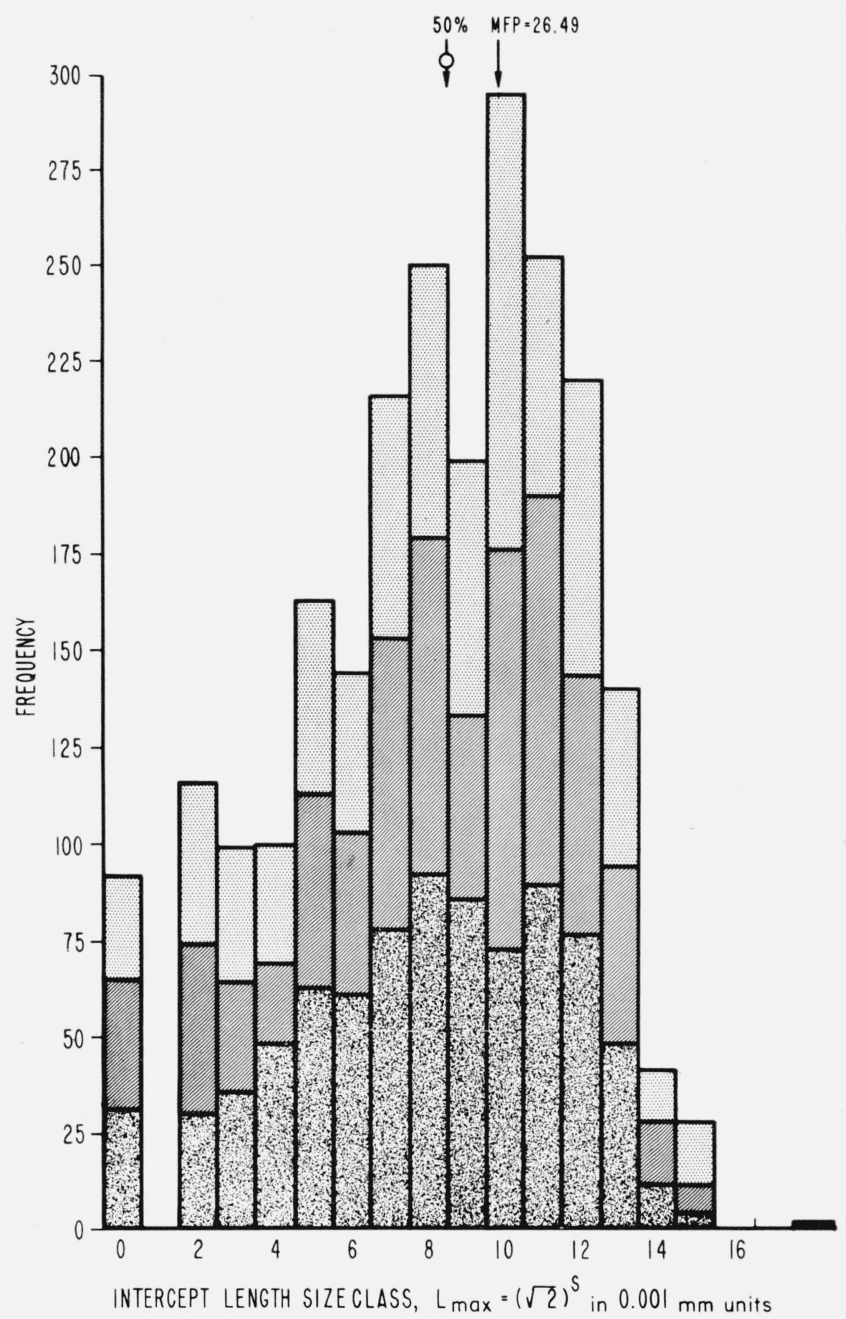

Figure 4. Histogram of line length distribution in the magenta phase ( $\left.\mathrm{Nb}_{3} \mathrm{Sn}\right)$.

divided to show the contributions from each of the three cuts, which will be observed to be of similar magnitude in each case. The class size interval for all distributions has been obtained by multiplying the next lower size interval by $\sqrt{2}$. For converience in labeling, plots are shown as frequency of occurrence versus a class size number " $S$ " such that $L \max =(\sqrt{2})^{S}$. Thus the maximum length included in "Class 10 " is $L \max =(\sqrt{2})^{10}=2^{5}$, which is 32 units in decimal notation, or 20 in the hexadecimal notation of the computer. Limits which would have fractional values are rounded to the next higher integer. Class $0(L=1)$ actually starts with a minimum value of 0.51 units, the lowest value seen by the computer (read as 1). Class 1, for which $L$ would be the unmeasurable value of 1.4 , is nonexistent in the present data. Thus classes " 0 " and " 2 " will contain some tallies which should properly belong in the nonexistent classes -1 and +1 , and should appear somewhat more populous than they 
would appear in a distribution obtained at higher resolution. The limits of all classes are given in both the decimal and hexadecimal notation in table 5 .

\begin{tabular}{|c|c|c|c|c|}
\hline \multirow{2}{*}{$\begin{array}{l}\text { Class } \\
\text { No. (S) }\end{array}$} & \multicolumn{2}{|c|}{ Decimal values } & \multicolumn{2}{|c|}{ Hexadecimal values } \\
\hline & Min & Max & Min & $\operatorname{Max}$ \\
\hline 0 & (0.51) & $\stackrel{1}{1}$ & $\begin{array}{r}(0.81) \\
\text { the present }\end{array}$ & 1 \\
\hline$\frac{1}{2}$ & \multicolumn{3}{|c|}{ nonexistent in the present data } & \\
\hline 3 & $2+$ & 3 & $\left(\begin{array}{ll}1.01) \\
2+\end{array}\right.$ & 3 \\
\hline & $3+$ & 4 & $3+$ & 4 \\
\hline 5 & 5 & 6 & 5 & 6 \\
\hline 6 & 7 & 8 & 7 & $8^{8}$ \\
\hline $\begin{array}{l}7 \\
8\end{array}$ & $\begin{array}{r}9 \\
12\end{array}$ & $\begin{array}{l}11 \\
16\end{array}$ & $\stackrel{9}{\mathrm{C}}$ & $\begin{array}{r}\mathrm{B} \\
10\end{array}$ \\
\hline 9 & 17 & 22 & 11 & 16 \\
\hline 10 & 23 & 32 & 17 & 20 \\
\hline 11 & 33 & 45 & 21 & $2 \mathrm{D}$ \\
\hline & 46 & 64 & $2 \mathrm{E}$ & 40 \\
\hline 13 & 65 & 90 & 41 & $5 \mathrm{~A}$ \\
\hline $\begin{array}{l}14 \\
15\end{array}$ & $\begin{array}{r}91 \\
129\end{array}$ & 128 & $5 \mathrm{~B}$ & 80 \\
\hline 16 & $\begin{array}{l}129 \\
182\end{array}$ & $\begin{array}{l}181 \\
256\end{array}$ & $\begin{array}{r}81 \\
\mathrm{BA}\end{array}$ & $\begin{array}{r}\text { B5 } \\
100\end{array}$ \\
\hline 17 & 257 & 362 & 101 & \\
\hline 18 & 363 & 512 & $16 \mathrm{~B}$ & 200 \\
\hline 19 & 513 & 724 & 201 & 2D 4 \\
\hline 20 & 725 & 1024 & $2 \mathrm{D} 5$ & 400 \\
\hline 21 & 1025 & 1448 & 401 & $5 \mathrm{~A} 8$ \\
\hline 22 & 1449 & 2048 & $5 \mathrm{~A} 9$ & 800 \\
\hline 23 & 2049 & $\begin{array}{l}2898 \\
4096\end{array}$ & 801 & B50 \\
\hline 24 & 2899 & 4096 & B51 & 1000 \\
\hline 25 & 4097 & 5790 & 1001 & $169 \mathrm{E}$ \\
\hline 26 & 5791 & 8192 & $169 \mathrm{~F}$ & 2000 \\
\hline & 8183 & 11575 & 2001 & 2D37 \\
\hline 28 & 11576 & 16384 & 2D38 & 4000 \\
\hline & 16385 & & & \\
\hline 30 & 23151 & 32768 & $5 \mathrm{~A} 83$ & 8000 \\
\hline
\end{tabular}

Note: Hexadecimal integers are: $0,1,2,3,4,5,6,7,8,9$, A, B, C, D, E, F, 10.

To interpret the line histogram in figure 4 , it is first necessary to recognize that the line intercepts of regular areas have a broader distribution than the sizes of the particles. For example, the intercepts of a circle whose caliper diameter is at the top of a size class are so distributed that only 70.5 percent are in the same size class as the diameter, while 29.5 percent are distributed among smaller size classes. The intercept distribution for a group of circles, all having diameters within one size class, is somewhat flatter. Such a distribution, obtained by the computer for circles in diameter class 10 , is illustrated in figure 5 .

In this light, it may be seen that the distribution of path length in the $\mathrm{Nb}_{3} \mathrm{Sn}$ phase (fig. 4) results from intercepting a wide range of $\mathrm{Nb}_{3} \mathrm{Sn}$ particle sizes. The occurrence of the 50 percentile point and of the average at positions close to the modal value indicates an essentially random nature for the distribution.

The summary statistics for the path lengths in $\mathrm{Nb}_{3} \mathrm{Sn}$ are shown in table 6 . The significant finding is that the mechanical mean free path averages only $26.5 \mu$, corresponding to 377 interruptions per centi-

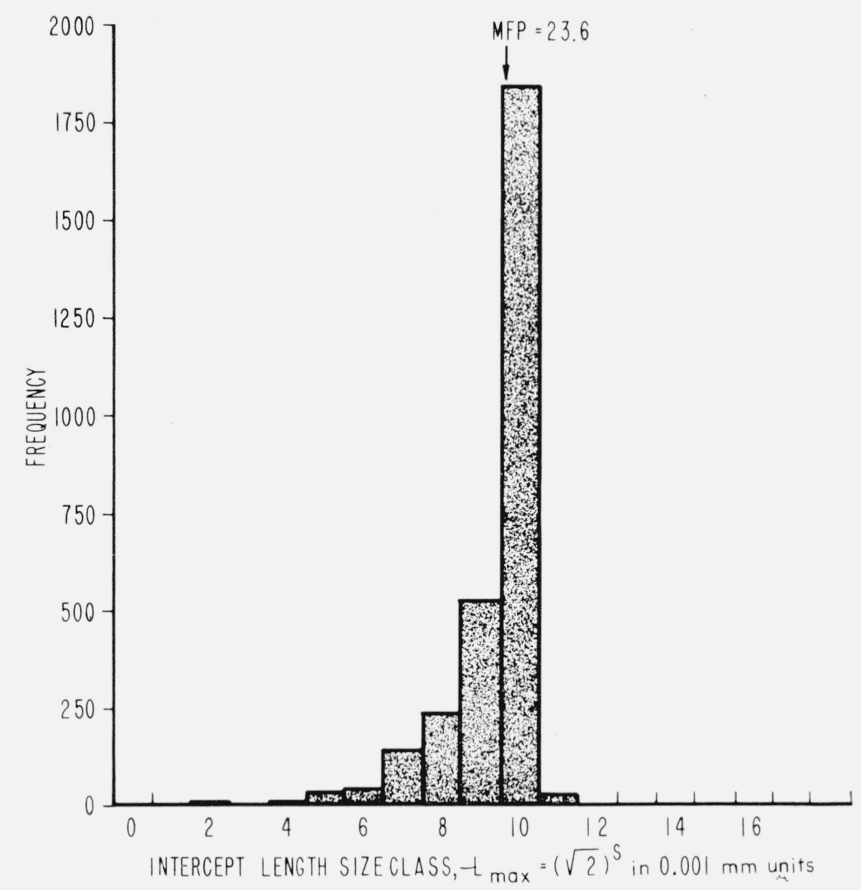

Figure 5. Histogram for comparison: distribution of line lengths for 100 circles whose caliper diameters are distributed over size class 10 (23 to 32 units).

meter. This value indicates a very large number of potential disturbances of orderly electron flow in a useful length of wire (footnote 3, p. 132). Also significant is the fact that the standard deviation of lengths is somewhat greater than the average length, which is to say that the distribution is very broad as compared with the usual chance distribution (such as Poisson and Binomial cases). This would imply that there is a good probability that the smaller particle sizes, or shorter paths, could be eliminated by more effective metallurgical treatment.

TABle 6. Summary statistics for lineal analysis of magenta images ( $\mathrm{Nb}_{3} \mathrm{Sn}$ phase)

1 unit $=0.001 \mathrm{~mm}$ on specimen

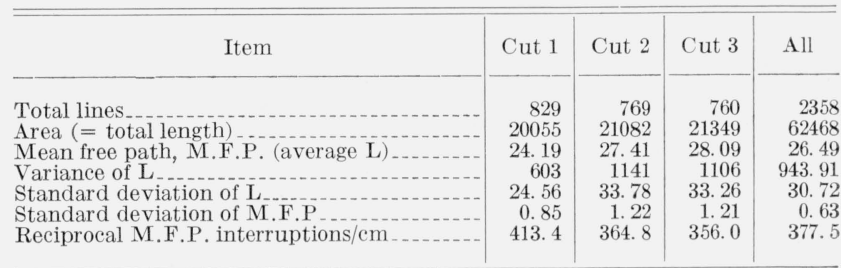

\section{Nature of the Interruptions}

The additional lineal data obtained from the 12 images may be examined primarily with the objective of evaluating the nature of the 2358 interruptions tallied along a line length of $62.5 \mathrm{~mm}$ in the $\mathrm{Nb}_{3} \mathrm{Sn}$ phase. 
A line distribution for all nonmagenta material (including holes) is shown in figure 6 . It may be seen that this distribution is more populous in the short length classes than that for the $\mathrm{Nb}_{3} \mathrm{Sn}$ (fig. 4) and that the whole background histogram lies about 3 classes to the left of the histogram for the magenta image; that is, that background intercepts are generally only about $1 / 3$ the length of $\mathrm{Nb}_{3} \mathrm{Sn}$ intercepts. The line intercept histograms for the Blue (high Nb) particles and for the Black holes are shown in figures 7 and 8 . It may be seen that the holes account for a majority of the interruptions. The summary statistics for these distributions are given in table 7 .

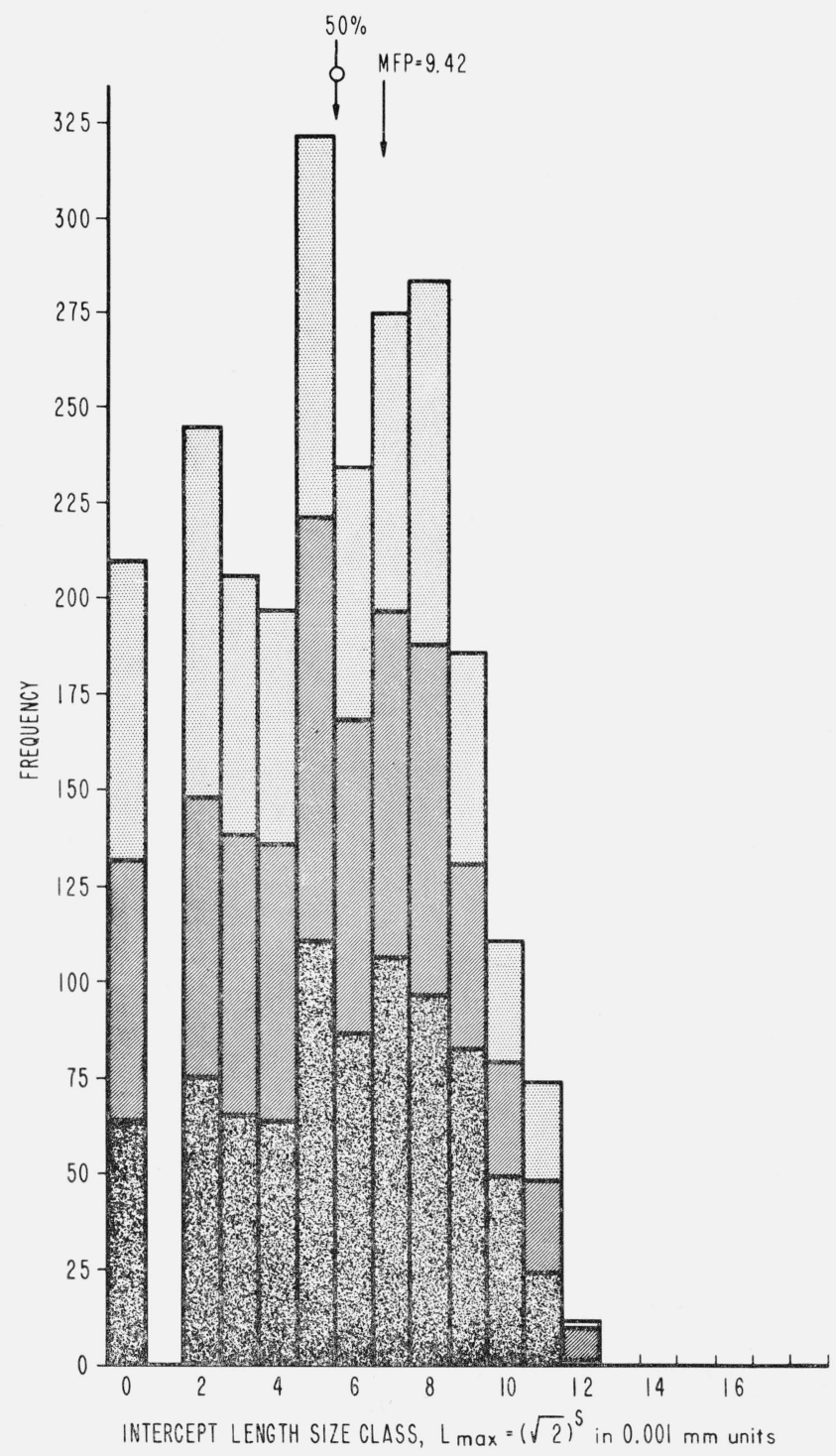

Figure 6. Histogram of line length distribution in the Nonmagenta (background) material.

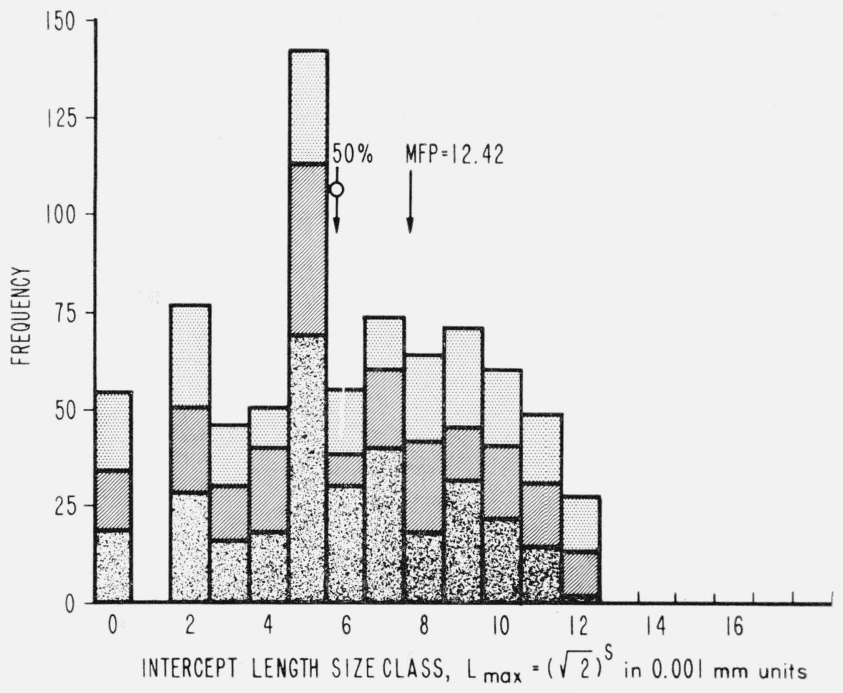

FIgURE 7. Histogram of line length distribution in the blue material $\left(\mathrm{Nb}+\mathrm{Nb}_{4} \mathrm{Sn}\right)$.

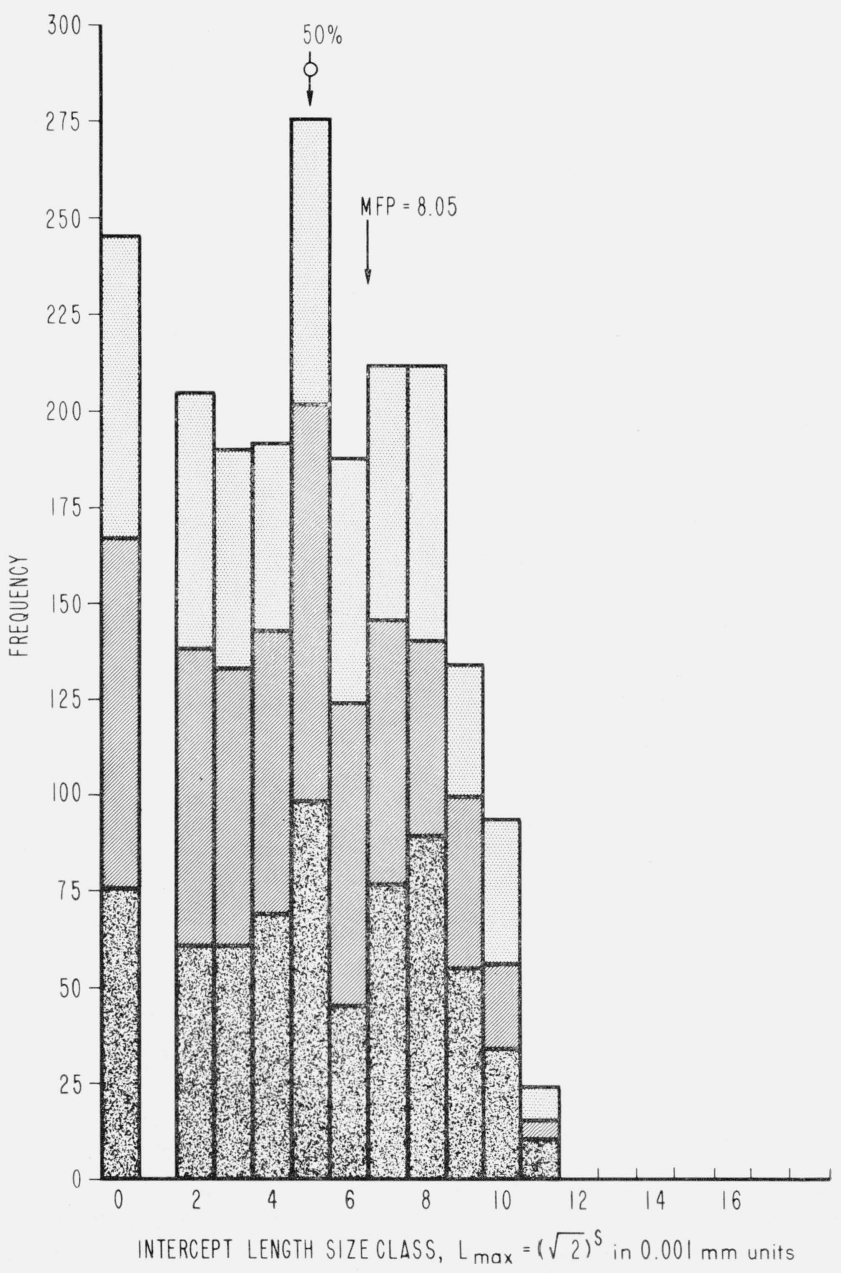

Figure 8. Histogram of line length distribution in the black voids. 
In only 3 of the 12 cases did the actual differences between the 3 determinations slightly exceed the $3 \sigma$ limit determined from the internal variance values, hence the slightly nonrepresentative nature of the 3 cuts is ignored and only the total of 3 runs considered.

TABLE 7. Summary statistics for lineal analysis of background, and of areas not $\mathrm{Nb}_{3} \mathrm{Sn}$

1 unit $=0.001 \mathrm{~mm}$ on specimen

\begin{tabular}{|c|c|c|c|c|c|}
\hline Item & $\begin{array}{l}\text { Back- } \\
\text { ground of } \\
\text { magenta }\end{array}$ & $\begin{array}{l}\text { All } \\
\text { blues }\end{array}$ & $\begin{array}{c}\text { All } \\
\text { blacks }\end{array}$ & $\begin{array}{c}\text { All } \\
\text { yel- } \\
\text { lows }\end{array}$ & $\begin{array}{l}\text { Total } \\
\text { not ma- } \\
\text { genta }\end{array}$ \\
\hline $\begin{array}{l}\text { Total lines } \\
\text { Area (total length) }\end{array}$ & $\begin{array}{r}2355 \\
22186\end{array}$ & $\begin{array}{r}771 \\
9576\end{array}$ & $\begin{array}{r}1967 \\
15836\end{array}$ & $\begin{array}{l}242 \\
900\end{array}$ & $\begin{array}{r}2980 \\
26312\end{array}$ \\
\hline $\mathrm{MFP}=$ A verage length, $\bar{L}$ & 9.42 & 12.42 & 8.05 & 3.72 & 8.83 \\
\hline Variance of $L$ & 86.95 & 170.93 & 61.84 & 10.84 & 91.76 \\
\hline & 9.32 & 13.07 & & 3. 29 & 9.58 \\
\hline Standard deviatio & 0.19 & 0.47 & 0.18 & 0.11 & 0.18 \\
\hline Interruptions......... percent_. & & 25.87 & 66.01 & 8.12 & 100. \\
\hline Background area_-_..-_percent_. & & 36. 39 & 60.18 & 3.42 & 100. \\
\hline $\begin{array}{l}1 / \bar{L}=\text { interruptions } / \mathrm{cm} \text { of path } \\
\text { in this material }\end{array}$ & 1061.5 & 805.1 & 1242.1 & 2688.9 & 1132.6 \\
\hline
\end{tabular}

It may be noted in table 7 that there were 625 cases (2980-2355) when the line trace passed from one nonmagenta area to a different nonmagenta area without first returning to the $\mathrm{Nb}_{3} \mathrm{Sn}$. The $(4 \%)$ excess in the area readings of the 4 sets of pictures now is found distributed among the minor constituents, with the compensating effect that the average line length is nearly the same in the direct background determination and in the sum of the three individual determinations.

It may be concluded from table 7 that the most important cause of interruptions of the $\mathrm{Nb}_{3} \mathrm{Sn}$ continuity is the voids. As many of these are small, they are more important than their share of the area would indicate. This disproportionate effect also is shared by the yellow $\mathrm{Nb}_{2} \mathrm{Sn}_{3}$ particles; however, these make only a minor contribution to the total effect. The blue Nb particles being on the average large, cause proportionally less interruption than their share of the area, and would presumably be regarded as less objectionable than the holes and $\mathrm{Nb}_{2} \mathrm{Sn}_{3}$ particles.

\section{Area Analysis}

The term "blob," is used in our computer terminology to designate any coherent object, no matter how complicated its shape, provided that some path, at least one computer unit wide, can be found from any one point in the blob to any other point in the same blob. No limit is placed on the complexity or length of the connecting path. So far as can be determined, no complication of the shape will itself result in a false identification. Although the computer may take a long time to find and transfer all of a complex shape, it will not report the blob * until no additional connective area can be found.
Thus a blob can be a single metal grain, provided the grain boundary is completely etched; or it can be a cluster of adhering grains of the same phase if the material is unetched, or if the grain boundaries are incompletely developed. As the specimen under study is anodized without etching, the second blob definition applies in the present case.

A typical BLTR print-out, again for Magenta Cut 1 , is shown in table 8 . As in table 4, five lines following "LIST": are the instructions from the operator to the computer, while all statements following "END" are the computers statements of progress and instructions by the computer to the operator concerning options and format. The BLTR output represents data in an intermediate form, intended for further statistical treatment by additional routines, hence is given in machine words and in hexadecimal notation. For economy, 11 items of information are incorporated into 4 words The positions of the hexadecimal point for each item have been indicated.

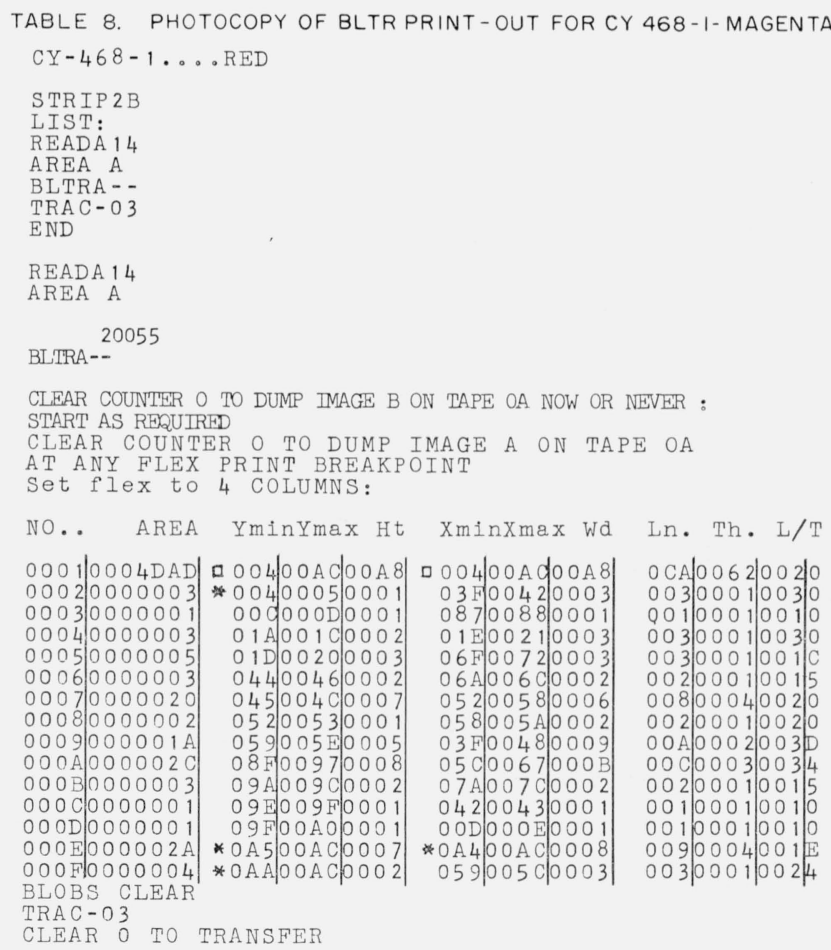

The first magenta cut is found to contain $\mathrm{F}=15$ "blobs." Of these, blob number 1 has an area of $4 \mathrm{DAD}=19885$ units, which is 99.15 percent of the total magenta area of 20055 units. The minimum and maximum addresses in $\mathrm{Y}$ (vertical, down) and $\mathrm{X}$ (horizontal, to right) are found to be the known edge addresses, 004 and $0 \mathrm{AC}$, respectively, hence this blob extends over the entire height and width of the image, but surrounds other small blobs to which it is not connected in the plane of the micrograph. It may also be noted that blobs numbered 
2, $\mathrm{E}$ and $\mathrm{F}$ also show one or two edge addresses, and thus touch some edge of the image. It should be presumed that their area of 49 units would have been found connected to the main blob if the cut had been made in a different position. The remaining 11 small blobs, containing 0.6 percent of the $\mathrm{Nb}_{3} \mathrm{Sn}$ area, cannot be proved to be connected to the main area, but very likely are so connected some place in the unseen volume.

The connectivity data for the three magenta cuts are summarized in table $9 . \quad$ As the three cuts overlap in the original micrograph, the three large blobs are all parts of one larger blob, which encompasses 99.6 percent of the observed $\mathrm{Nb}_{3} \mathrm{Sn}$ area, and occupies 70 percent of the volume observed. Thus, at least one convoluted but continuous path can be traced between two points at least $140 \mathrm{~mm}$ apart in the picture $(560 \mu$ in specimen). There is every reason to presume that at least one such continuous path would extend (in volume) through the length of the wire even if the observable path should be found to terminate somewhere on the particular plane examined. Therefore, if the magenta phase is in fact a good superconductor, and this micrograph represents a low quality superconductor, the cause of this low quality must be presumed to lie in the short linear paths (or in restricted cross sections), not in lack of connectivity in the absolute sense.

TABLE 9. Connectivity of $\mathrm{Nb}_{3} \mathrm{Sn}$ phase; magenta images - complex paths

1 area unit $=1 \times 10^{-6} \mathrm{~mm}^{2}$ on original

\begin{tabular}{|c|c|c|c|c|}
\hline Item & Cut 1 & Cut 2 & Cut 3 & Total \\
\hline Area of phase. & 20055 & 21082 & 21349 & 62486 \\
\hline Area, main blob. & 19885 & 20882 & 21294 & 62061 \\
\hline Main blob. & 99.15 & 99.05 & 99.74 & 99.32 \\
\hline Number edge blobs . & 3 & 5 & 3 & 11 \\
\hline Area in edge blobs.. & 49 & 143 & 8 & 200 \\
\hline In edge blobs..... & 0.24 & 0.68 & 0.04 & 0.32 \\
\hline Presumed connective & 99.40 & 99.73 & 99.78 & 99.64 \\
\hline No. disconnected blobs. & 11 & 11 & 8 & \\
\hline Area, disconnected & 121 & 57 & 47 & 225 \\
\hline Disconnected & 0.60 & 0.27 & 0.22 & 0.36 \\
\hline Total volume connective & 67.42 & 71.65 & 71. 28 & 70.12 \\
\hline
\end{tabular}

\section{Particle Size Distributions}

A further statistical description of the nature of the areas which interrupt the $\mathrm{Nb}_{3} \mathrm{Sn}$ phase can be obtained by constructing histograms of the additional parameters given by the BLTR analyses. Since the machine coding for these operations has not been completed, the tallies were made manually from the BLTR print-out in the same manner as performed by the machine in the LINE operation. These tallies thus may also serve to determine the utility which may be expected from the next phase of the computer programming.

The distributions of blue, black, and yellow blobs according to area classes are shown in figures 9-11. Since, on logarithmic classes, a blob having height in class 7 and a width in class 5 should have an area in class 12 , the scale of the abscissa is now reduced by a factor of two. Peaks due to the same groups of particles will thus fall in the same physical position on the graphs in both area and length plots.

The "raw" distributions are obtained by tallying. the blob areas stated by the computer, without regard to the fact that some blobs have been cut by the edges of the pictures, and are therefore larger than stated. In the "edge corrected" distributions blobs which had edge addresses were tallied as half blobs twice as large (two classes larger), and corner blobs as quarter blobs four classes larger. This treatment has essentially the same effect as the half grain convention normally used with the Jeffries method of grain size determination. ${ }^{5}$

Both forms of the area distributions show essentially similar patterns, the average area being increased only a fraction of one class by edge correction. The displacements between the 50 percentile points, modes, and averages show these distributions to be abnormal. This is due to the presence of concentrations of very small areas, the presence of which was not entirely obvious in the line distributions. In the case of the black voids, a very high concentration of unit areas (class 0 ; area $=10^{-6} \mathrm{~mm}^{2}$ ) is the most prominent feature of the histograms.

${ }_{5}$ The circular format used in the Jeffries method [13] is advantageous in manual counting, since a circle of exactly known area is easily constructed. Establishing a circular border in the computer would be a complex operation involving greater error than that due to the $4 / \pi$ increase in border length due to the square format; hence the square format is dictated for computer use.

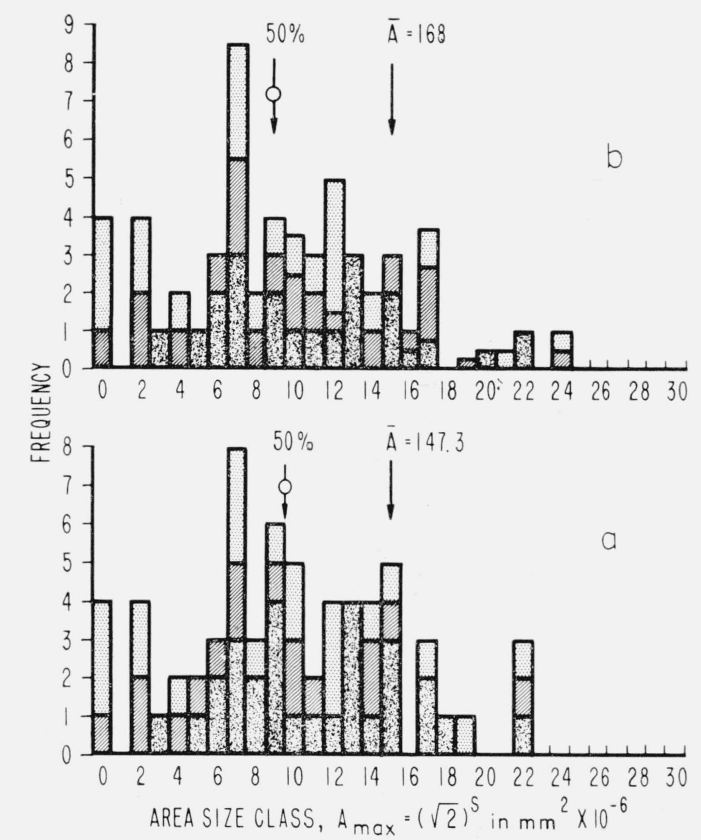

Figure 9. Histogram of area class distribution for blue particles $(\mathrm{Nb}+\mathrm{Nb} \mathrm{Sn})$.

(a) Raw data.

(b) Data corrected for edge cutting. 

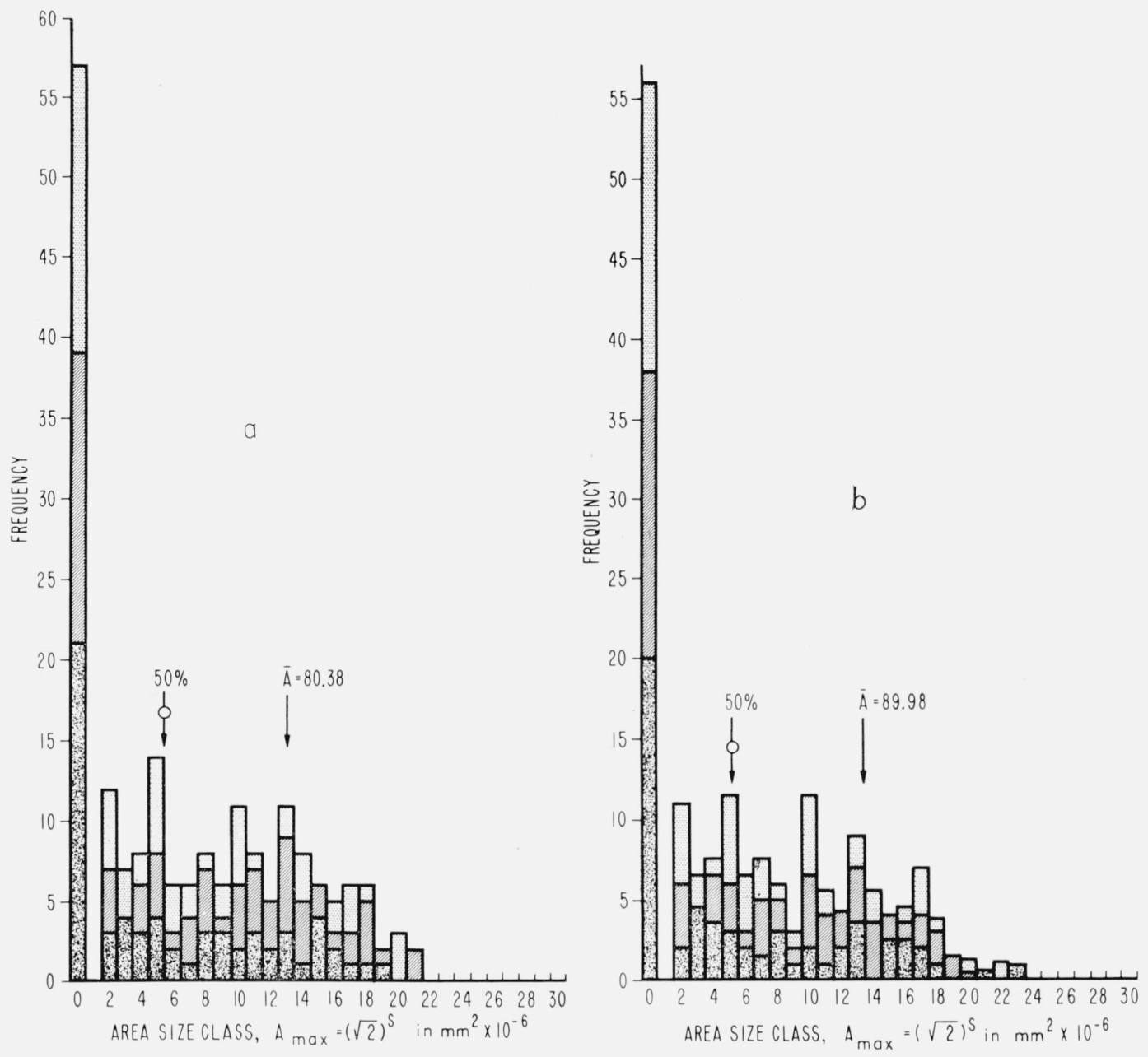

Figure 10. Histogram of area class distribution for black voids.

(a) Raw data.

(b) Data corrected for edge cutting.

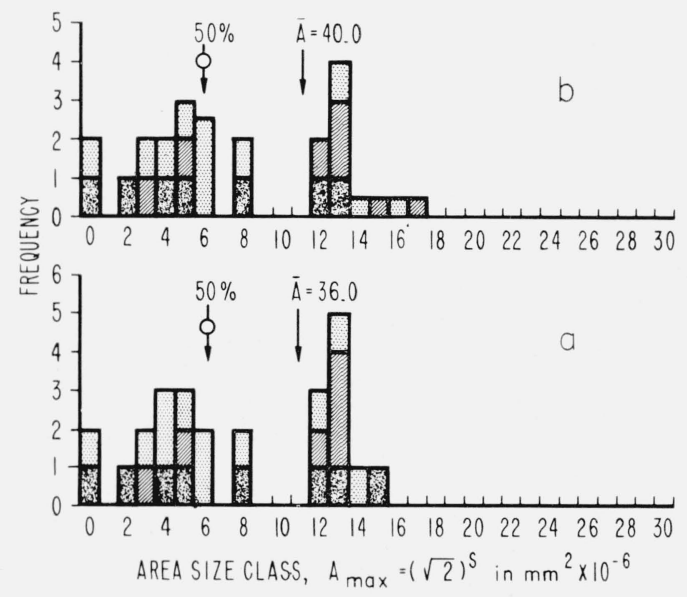

Figure 11. IIistogram of area class distribution for yellow particles $\left(\mathrm{Nb}_{2} \mathrm{Sn}_{3}\right)$.

(a) Raw data.
(b) Data corrected for edge cutting. 
If one ascribes all of the unit areas to spherical voids of unit volume (a crude approximation) it may be estimated that $1 \mathrm{~mm}^{3}$ of the core material contains $6.6 \times 10^{5}$ such voids of a verage volume $=10^{-9} \mathrm{~mm}^{3}$, as compared with about 25000 voids of volume class $15 \quad\left(V \quad \max =181 \times 10^{-9} \mathrm{~mm}^{3}\right)$, which are mainly responsible for the mode at class 5 in the lineal analysis.

If nearly a million voids per cubic millimeter were caused by improper packing - that is by failure of tin to fill the spaces between the original niobium particles, than a majority of these particles would have had to be in diameter class 7 (9 to $11 \mu)$. Such an assumption is contradicted by the presence of blue residues in area class 22 and height and width classes 12 and 13 (figs 12 and 14). It would thus seem apparent that the original niobium powder was of the common 200 mesh grade (diameter class 12) and therefore consisted of only around 5000 grains $/ \mathrm{mm}^{3}$. Since there are apparently more than 100 small voids per original niobium grain, it must be assumed that these small voids must have resulted from the Nb-Sn diffusion reaction and not from poor packing, Metallurgically, this might result either from decomposition of some compound of niobium and a gas, or from the Kirkendall effect in the diffusion.

\section{Height, Width, and Length}

The parameter "height" in the BLTR routine output is the calliper dimension of a particle in the vertical dimension of the image as seen by the computer. In the present pictures, height is perpendicular to the axis of the wire. Histograms for this parameter are shown in figures 12 and 13 .

"Width" is the corresponding caliper dimension in a direction parallel to the wire axis. Histograms are shown in figures 14 and 15 . These two sets of histograms share some of the properties of the area histograms, in that the abnormal abundance of small holes can be more clearly detected than in the lineal analysis, where the multiple traces from larger particles overshadow the single traces from the smallest particles.

The height and width histograms can be compared to detect preferred orientation or elongation of particles. In the case of the blue (niobium) material, the mean width, $14.16 \mu$, exceeds the mean height, $10.69 \mu$, by almost a factor of $\sqrt{2}$, which is a strong indication that the niobium particles were rotated in the soft tin matrix during the production of the wire. However, if the niobium grains had themselves been appreciably cold-worked, they would then be expected to have been elongated to an extent approaching the final length/diameter ratio attained by a hypothetical cube of metal from the original niobium sheath; which ratio is computed as 3815 , (for a diameter reduction of 15.6 times). As actual width to height ratios of at least 100 can be observed in an etched micrograph of the sheath, it is apparent that the niobium grains remaining in the core were not subject to any significant amount of

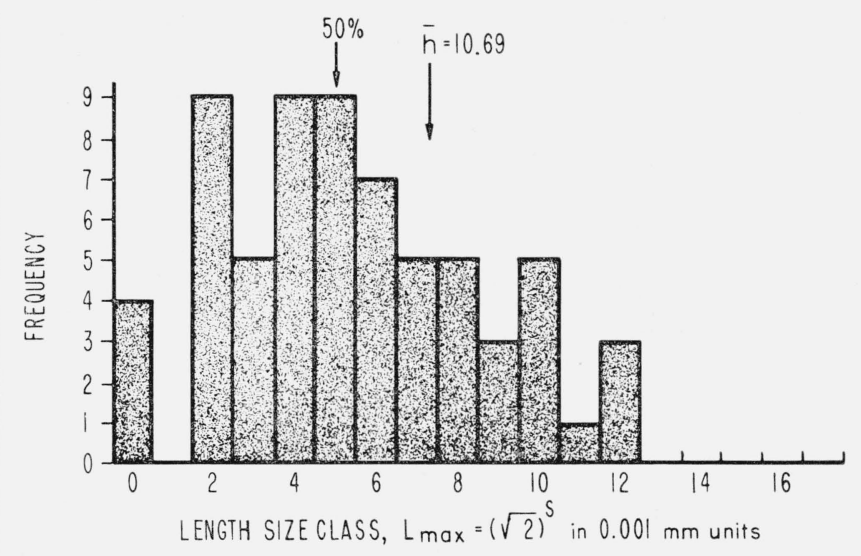

Figure 12. Histogram of height distribution for blue particles $(\mathrm{Nb}+\mathrm{Nb}, \mathrm{Sn})$.

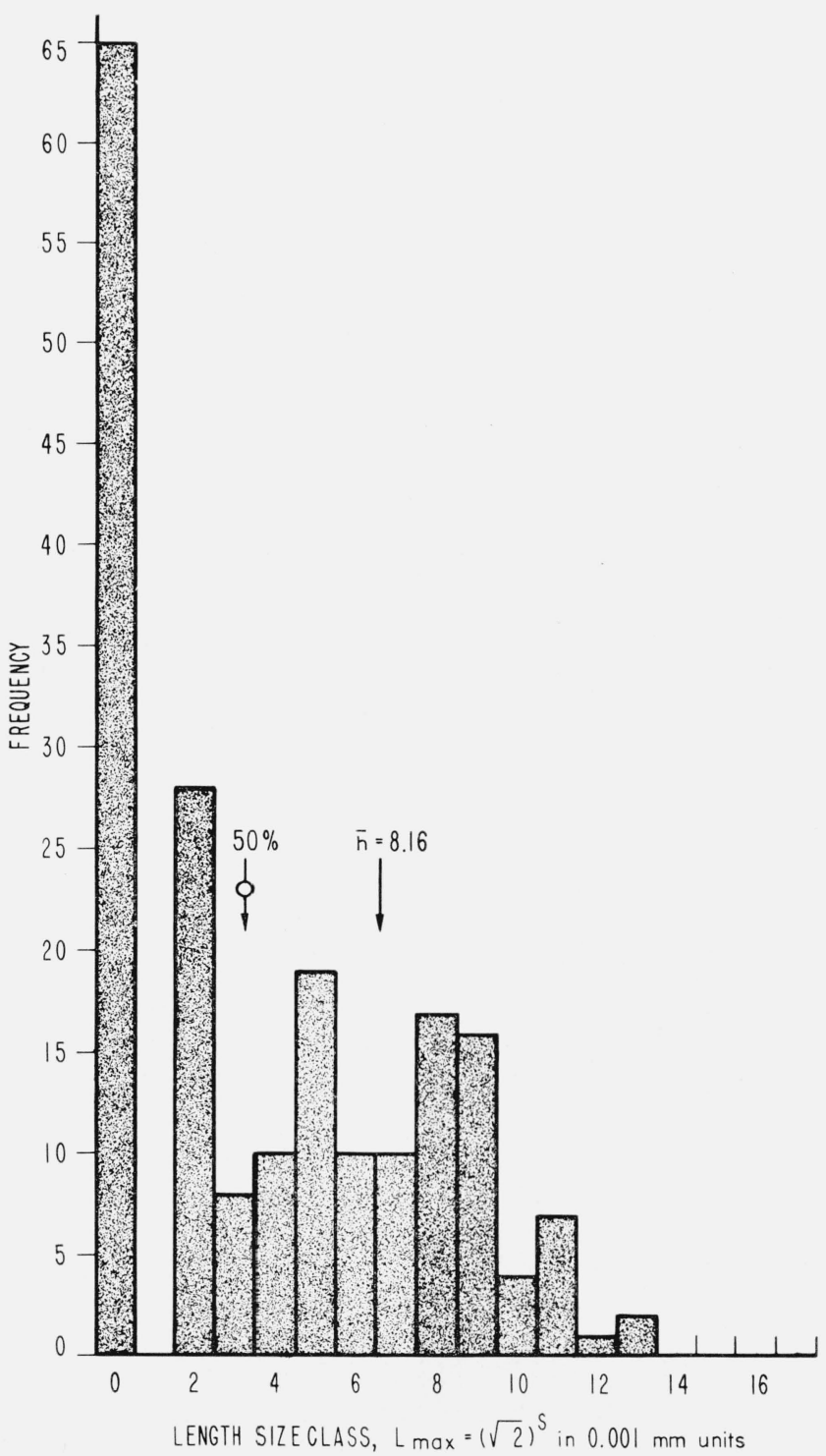

FIGURE 13. Histogram of height distribution for black voids. 


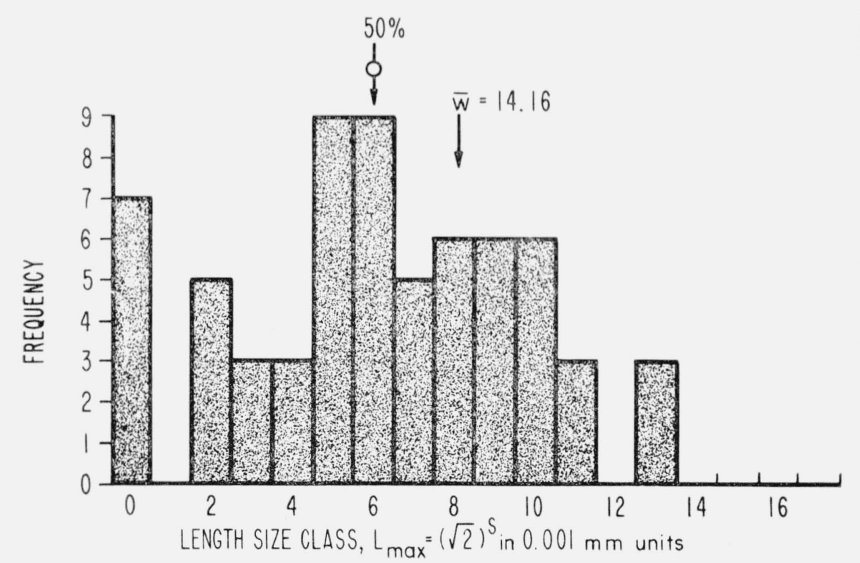

Figure 14. Histogram of width distribution for blue particles $\left(\mathrm{Nb}+\mathrm{Nb}_{4} \mathrm{Sn}\right)$.

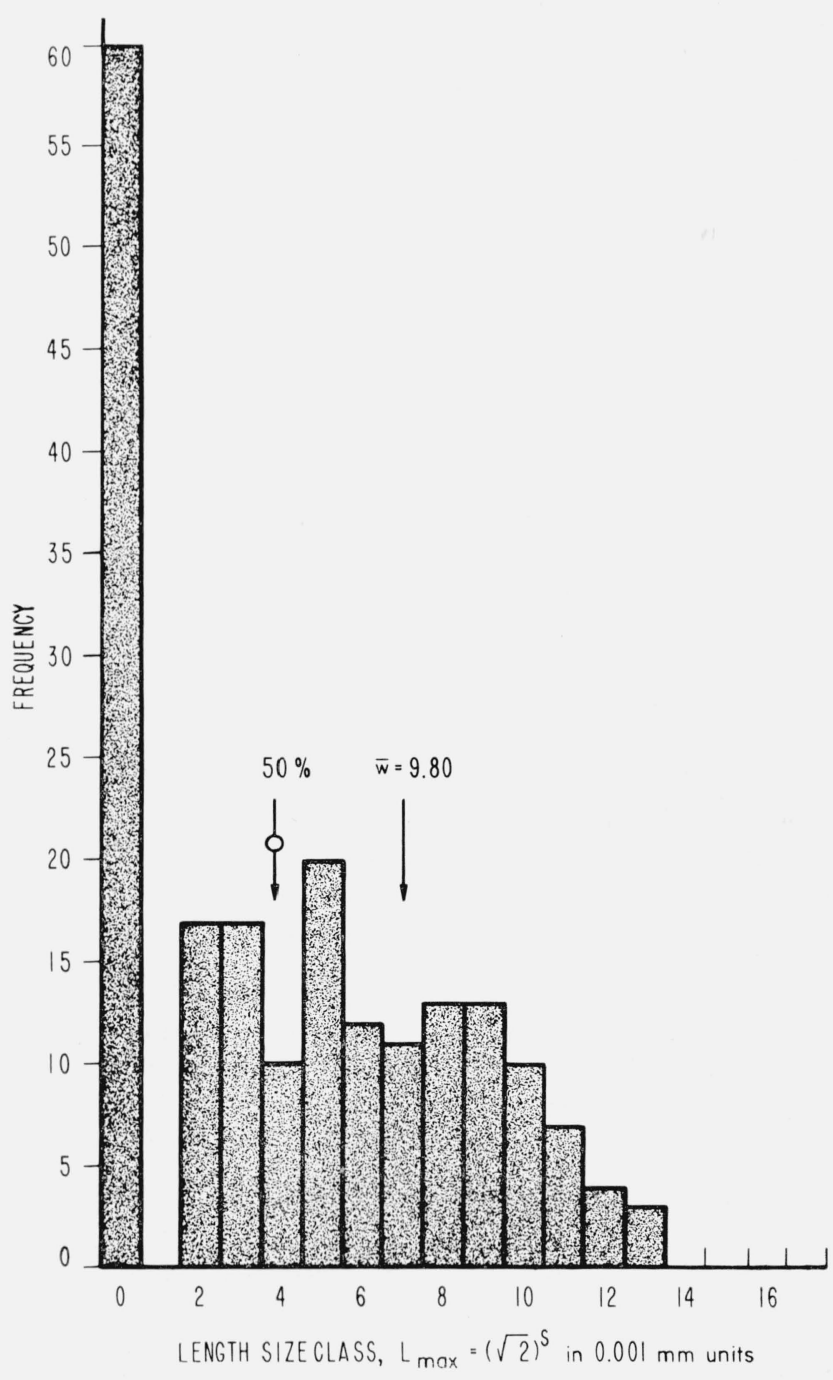

Figure 15. Histogram of width distribution for black voids. coldwork, and that the anisotropy of dimensions is probably only that existing in the original niobium powder.

The average ratio of width to height for voids is 9.80 to 8.16 or 1.20 ; hardly a significant departure from symmetry. Voids which resulted from incomplete packing of the original powders would have been elongated even more easily than the particles of soft tin. Thus it again appears clear that the observed voids are not held over from the packing of the powders.

"Length" is an estimated value taken as the average of the longer of the two measured dimensions and the maximum diagonal of the circumscribed rectangle. The approximation is adequate to place the largest dimension of the section in the correct size class, with a maximum error of $1 / 2$ class. Length histograms are shown in figures 16 and 17 . These are somewhat more regular than the corresponding height or width histrograms, but do not appear to disclose any new information in the present case. The increase of average length over average width is only that inherent in the computation.

The division of blob area by estimated length gives a value for the estimated mean thickness. The ratio of the length to this thickness gives a shape factor whose values lie from $17 / 16$ to 2 for equiaxed particles. High values indicate a complex shape, and are mainly useful to permit the computer to recognize blobs which are in fact clustered grains which should be subdivided in computing a standard grain size distribution. Histograms of this factor show only that many of the blue grains and holes are not equiaxed. Such histograms are therefore omitted from this report.

\section{Summary}

Methods have been developed whereby a metallurgical micrograph can be shown to the digital computer SEAC, which may then be instructed to determine a number of useful parameters in the fields of lineal analysis and of particle size measurements. The elementary computer processes which make such measurements possible have been described, together with an outline of the manner in which many elementary operations can be combined into practical working routines. Such working routines can thereafter be applied to practical problems by operators who are not required to be familiar with the details of the actual computer program.

To illustrate routines already operating at the practical level, and to explore the possible significance of the data produced, the authors have chosen to show a detailed analysis of a color micrograph of what is believed to be a low quality specimen of the superconductor $\mathrm{Nb}_{3} \mathrm{Sn}$. In addition to its possible significance in the problem of producing higher quality superconducting devices, this micrograph presents analytical problems considerably greater than those which have normally been encountered in micrographic sections of other, and usually less complex, materials which have been quantitatively analyzed by hand methods. 


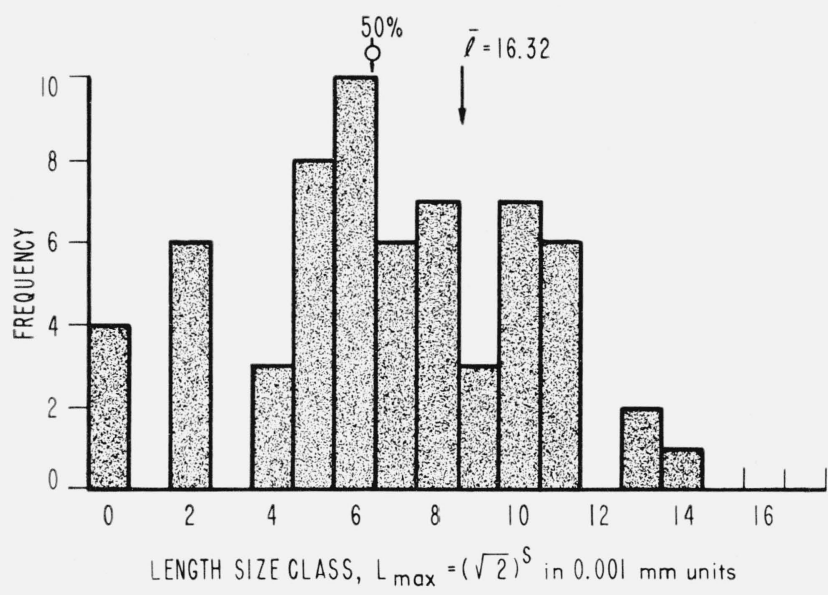

Figure 16. Histogram of length distribution for blue particles $\left(\mathrm{Nb}+\mathrm{Nb}_{4} \mathrm{Sn}\right)$.

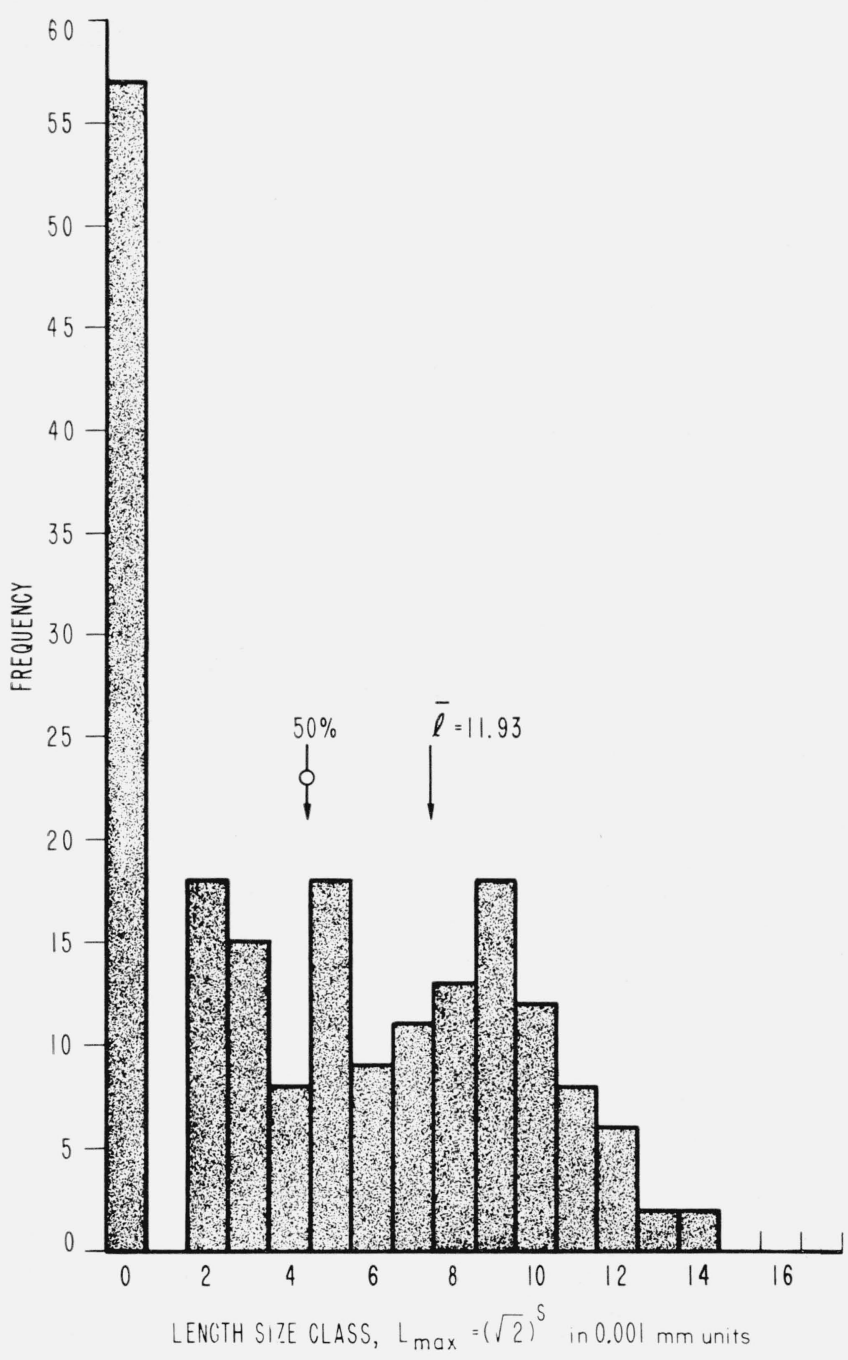

Figure 17. Histogram of length distribution for black voids.
The micrograph analyzed actually showed evidence of five solid constituents in addition to voids. Inasmuch as two of these constituents were in very small concentration, it was considered sufficient to make four color-separations, each showing one of the four major constituents. Three separate areas of each color were analyzed, with one being deliberately chosen to look "better" than the others. This "best" area proved, however, not to be significantly different from the others on a statistical basis.

The relative amounts of the four constituents were determined within a precision of about 1 percent, and the composition of the $\mathrm{Nb}_{3} \mathrm{Sn}$ phase was computed with good agreement among the three tests and an absolute value within 1.3 percent of the stoichiometric value. Computations of variance indicate that differences between the sections of the micrograph are responsible for errors approximately four times as great as those inherent in the point sampling process used (as computed from the binomial distribution).

Parameters of possible significance in defining a high quality superconductor were measured, viz, the mechanical mean free path in each constituent, and the distributions of particle area, height, width, and length in each. The poor material was found to contain 70 percent by volume of the $\mathrm{Nb}_{3} \mathrm{Sn}$ phase, of which 99.6 percent was interconnected by one or more paths (often complex). It does not appear reasonable to expect that an additional increase in absolute connectivity by a fraction of 1 percent would appreciably improve the superconducting quality.

The mechanical mean free path in the $\mathrm{Nb}_{3} \mathrm{Sn}$ phase was found to be only $26.5 \mu$. This represents an upper limit to the electronic mean free path in this phase, and a value low in the range which has been reported for good superconductors.

The interruptions of this mean free path are assigned mainly to the voids in the structure, with lesser portions due to residual high-niobium particles, and a small part due to high-tin material. The highniobium particles are found to have been rotated during the working of the wire, but not to have themselves been significantly elongated or cold worked. The voids do not show evidence of elongation, and are found to exist in numbers of the order of 100 times the abundance which might reasonably be assigned to inadequate packing of the original mixture. The voids thus may be presumed to have originated in the reaction between tin and niobium, either by the Kirkendall effect or perhaps by decomposition of some compound of niobium and a gas.

It must however be emphasized that the actual role of the observed defects in the superconducting process must remain hypothetical until there are available, for quantitative metallographic analysis, micrographs of actual sections from good and bad wires, whose superconducting quality has been accurately measured. When numerical correlations can be made between a numerical index of superconducting quality and the various measurable micrographic parameters, it will be possible to determine which of these parameters are in fact significant. 
With the presently available computer methods, data comparable to those illustrated in this report are no longer prohibitive to obtain. The present data were obtained in slightly over $2 \mathrm{hr}$ of actual computer operation, at a nominal computer charge of less than $\$ 200$. In this analysis, the computer performed around 8 million individual arithmetical and logical operations. As some of the necessary data processing steps had not yet been coded for the computer, an estimated 20 thousand equivalent elementary operations were performed by hand, at a cost of around 100 man hours. Based on these estimates, the cost of acquiring quantitative metallographic information by computer may be less than 1 percent of the cost to perform the same processes with equal accuracy by hand.

Programming is in process for a "slice" analysis to determine variations in cross sections, and for a more accurate measurement of grain circumferences, as well as for the computation of the histograms for the particle size analysis. Means are available for the direct machine plotting of the histograms from the computer output. When all steps of the analytical process have been mechanized, it will be entirely feasible to deliver completed diagrams of the distributions of the desired parameters within minutes of the delivery to the computer of suitable photomicrographs. Once all parts of this programming have been worked out on the present size scale, the routines are expected to be duplicated for a larger computer (PILO'T) where work can be done on the $8 \times 10$ in. $(20 \times 25 \mathrm{~cm})$ scale with an expected accuracy in the 0.1 percent range.

While the present illustration has been taken from the field of optical metallography, the computer processes are in no way dependent on the actual nature of the original material, or on the magnification or kind of microscope used. The same computer programs may be applied directly to petrographic subjects, and to many similar biological problems, and, on any size scale, to any similar counting or measuring problem in which the original information can be represented in a suitable photograph. Further exploration may be expected to show many useful applications for geometrical parameters which have heretofore been neglected because of the labor required for measuring such parameters by hand methods.

Sincere thanks are extended to Dr. M. L. Picklesimer of the Oak Ridge National Laboratory for supplying color micrographs of actual Nb-Sn superconductor wires.

Mr. R. B. Thomas of the NBS Data Processing Systems Division compiled the basic library of image processing routines used and has supplied valuable advice and help in composing additional analytical routines.

Mr. H. M. Joseph has assisted in the composition of the new routines and in the operation of the computer during the present study.

\section{References}

[1] Quantitative Metallography, F. N. Rhines (Ed.) (McGraw-Hill Book Co., Inc., New York, N.Y., in Press). Chapter 15: Comments on the possibilities of performing quantitative metallographic analyses with a digital computer, G. A. Moore, L. L. Wyman, and H. M. Joseph.

[2] R. A. Kirsch, Processing pictorial information with digital computers, A.I.E.E., CP 57-878 (1957). R. A. Kirsch, L. Cahn, C. Ray, and G. H. Urban, Experiments in processing pictorial information with a digital computer, p. 221, Proc. Eastern Joint Computer Conference (1957).

[3] (a) B. T. Matthias, T. H. Geballe, S. Geller, and E. Covenzwit, Superconductivity of $\mathrm{Nb}_{3} \mathrm{Sn}$, Phys. Rev. 95, 1435 (1954). (b) J. E. Kunzler, E. Buchler, F. S. L. Hso, and J. H. Wernick, Superconductivity in $\mathrm{Nb}_{3} \mathrm{Sn}$ at high current density in a magnetic field of 88 Kgauss, Phys. Rev. Letters 6, 89 (1961).

[4] V. D. Arp, R. H. Kropschot, and J. H. Wilson, Superconductivity of $\mathrm{Nb}_{3} \mathrm{Sn}$ in pulsed fields of 185 kilogauss, Phys. Rev. Letters 6, (9) 452 (1961).

[5] (a) R. McFee, Applications of superconductivity to the generation and distribution of electric power, Electrical Engineering $81 / 2(2 / 62) 122-129$. (b) F. Bitter, Strong magnets, International Science and Technology $1 / 4$ (Apr. 1962) 58-64.

[6] G. A. Moore, The comportment of the palladiumhydrogen system toward alternating electric current, Journal of Electrochem. Soc. 75, 237-267 (1939).

[7] F. B. Hagedorn, Dependence of superconductingtransition temperature on residual, electronic mean free path in tin thin films, Bul. Am. Phys. Soc. 11, $7 / 3$ p. 175 (Mar. 26, 1962).

[8] L. L. Wyman, J. R. Cuthill, G. A. Moore, J. J. Park, and H. Yakowitz, Intermediate phases in superconducting niobium-tin alloys, Journal of Research of the NBS 66A (Phys, and Chem.) No. 4, 351-363 (JulyAug. 1962)

[9] M. L. Picklesimer, Anodizing as a metallographic technique for zirconium base alloys, U.S. Atomic Energy Commission, ORNL 229613 p. (1957).

[10] A. Maerz and M. R. Paul, Dictionary of Color (MeGrawHill Book Company, Inc., New York, New York 1930).

[11] Welding Handbook, 3d Edition, Am. Welding Society, 1950, Table p. 1023.

[12] B. I. Edelson and W. M. Baldwin, Jr., The Effect of second phases on the mechanical properties of alloys, Trans. Am. Soc. Met. 55 [1] 230-250 (Mar. 1962).

[13] ASTM Designation E112-61, Standard methods for estimating the average grain size of metals.

[14] L. L. Wyman and G. A. Moore, Quantitative metallographic evaluations of graphitic microstructuresmodern castings 43 [1] 7-16 (Jan. 1963). 